\title{
1 Isoprene versus Monoterpenes as Gas-Phase Organic Acid Precursors in the
}

2 Atmosphere

3 Michael Link; Patrick Brophy; S. Ryan Fulgham; Trey Murschell; Delphine K. Farmer

4 1. Supplemental site descriptions

5 SOAS. Median daytime temperatures during SOAS were around $29^{\circ} \mathrm{C}$ while temperatures in the evening

6 dropped to around $21^{\circ} \mathrm{C}$. Relative humidity $(\mathrm{RH})$ was lowest during the day $(\sim 60 \%)$ and increased in the

7 evening often above $90 \%$. A period of cloud cover (i.e., decreased solar radiation) was observed from

8 July $3^{\text {rd }}$ to the $7^{\text {th }}$. This resulted in decreased photochemistry as evidenced by low $\mathrm{HO}_{2}$ and $\mathrm{O}_{3}$ mixing

9 ratios. Coincident with the measurements of organic acids, the most precipitation was observed between

10 July 3-7 totaling $51.7 \mathrm{~mm}$ with an additional $18.5 \mathrm{~mm}$ of precipitation observed at different times during

11 the three-week measurement period. Occasional influence of anthropogenic emissions on the site was

12 observed as evidenced by spikes in $\mathrm{SO}_{2}$ mixing ratios.

13 FIXCIT experiment summary. Organic acids were quantified from eight experiments from FIXCIT. Important conditions for each of the experiments are shown below in Table S1.

\begin{tabular}{|c|c|c|c|c|c|}
\hline $\begin{array}{c}\text { Date of } \\
\text { experiment }\end{array}$ & $\begin{array}{l}\text { Precursor and } \\
\text { conditions }\end{array}$ & RH & $\begin{array}{l}\text { Background } \\
\text { subtraction }\end{array}$ & Oxidant exposure & Comments \\
\hline 01.02 .14 & $\begin{array}{l}\text { Isoprene }+\mathrm{OH} \\
\text { ("low NO") } \\
\text { Isoprene }+\mathrm{OH}\end{array}$ & $<5 \%$ & $\begin{array}{l}\text { "low NO" } \\
\text { OH blank } \\
\text { "high NO" }\end{array}$ & $\begin{array}{l}2.2 \times 10^{10} \text { molecules } \mathrm{s} \\
\mathrm{cm}^{-3} \\
2.2 \times 10^{10} \text { molecules } \mathrm{s}\end{array}$ & \\
\hline 01.03 .14 & ("high NO") & $<5 \%$ & $\begin{array}{l}\text { OH blank } \\
\text { Pre- }\end{array}$ & $\mathrm{cm}^{-3}$ & \\
\hline 01.06 .14 & Isoprene $+\mathrm{O} 3$ & $<5 \%$ & $\begin{array}{l}\text { hydrocarbon } \\
\text { injection } \\
\text { Pre- } \\
\text { hydrocarbon }\end{array}$ & $8.1 \times 10^{6} \mathrm{ppb}_{\mathrm{v}} \mathrm{s}$ & $\begin{array}{l}\text { No } \mathrm{OH} \\
\text { scavenger added } \\
\text { atmospherically- } \\
\text { relevant } \mathrm{HO}_{2}\end{array}$ \\
\hline 01.09 .14 & $\begin{array}{l}\text { Isoprene }+\mathrm{NO} 3 \\
\alpha \text {-pinene }+\mathrm{OH}\end{array}$ & $<5 \%$ & $\begin{array}{l}\text { injection } \\
\text { "low NO" }\end{array}$ & $\begin{array}{l}- \\
5.3 \times 10^{10} \text { molecules } \mathrm{s}\end{array}$ & mixing ratios \\
\hline 01.10 .14 & $\begin{array}{l}\text { ("low NO") } \\
\alpha \text {-pinene }+\mathrm{OH}\end{array}$ & $<5 \%$ & $\begin{array}{l}\text { OH blank } \\
\text { "high NO" }\end{array}$ & $\begin{array}{l}\mathrm{cm}^{-3} \\
4.8 \times 10^{10} \text { molecules } \mathrm{s}\end{array}$ & \\
\hline 01.11 .14 & ("high NO") & $<5 \%$ & $\begin{array}{l}\text { OH blank } \\
\text { Pre- }\end{array}$ & $\mathrm{cm}^{-3}$ & \\
\hline 01.14 .14 & Isoprene $+\mathrm{O} 3$ & $<5 \%$ & $\begin{array}{l}\text { hydrocarbon } \\
\text { injection } \\
\text { Pre- }\end{array}$ & $9.57 \times 10^{6} \mathrm{ppb}_{\mathrm{v}} \mathrm{s}$ & $\begin{array}{l}\text { cyclohexane } \mathrm{OH} \\
\text { scavenger }\end{array}$ \\
\hline 01.29 .14 & Isoprene $+\mathrm{O} 3$ & $50 \%$ & $\begin{array}{l}\text { hydrocarbon } \\
\text { injection }\end{array}$ & $7.57 \times 10^{6} \mathrm{ppb}_{\mathrm{v}} \mathrm{s}$ & $\begin{array}{l}\text { Cyclohexane } \mathrm{OH} \\
\text { scavenger }\end{array}$ \\
\hline
\end{tabular}

Table S1. Summary of FIXCIT experiments analyzed.

\section{Acetate CIMS data treatment.}

Data processing and mass calibration. All CIMS data were processed using Tofware v2.5.12 in Igor Pro 7. Mass calibrants varied slightly between all campaigns and lab experiments but common calibrants included $\mathrm{O}_{2}^{-}(\mathrm{m} / \mathrm{z} 31.99), \mathrm{NO}_{3}^{-}\left(\mathrm{m} / \mathrm{z}\right.$ 61.99), $\mathrm{CHO}_{2}^{-}(\mathrm{m} / \mathrm{z} 45.00), \mathrm{C}_{4} \mathrm{H}_{7} \mathrm{O}_{4}{ }^{-}(\mathrm{m} / \mathrm{z} 119.03), \mathrm{C}_{2} \mathrm{H}_{3} \mathrm{O}_{2}{ }^{-}(\mathrm{m} / \mathrm{z}$ 59.01) and $\mathrm{CF}_{3}{ }^{-}\left(\mathrm{m} / \mathrm{z}\right.$ 68.99). A calibrant that was used unique to SOAS was $\mathrm{C}_{12} \mathrm{H}_{20} \mathrm{NO}_{7}^{-}(\mathrm{m} / \mathrm{z} 290.12)$, presumably a sesquiterpene hydroxynitrate. During Spiffy $\mathrm{C}_{18} \mathrm{H}_{35} \mathrm{O}_{2}{ }^{-}(\mathrm{m} / \mathrm{z} 288.26)$ was used as a mass

23 calibrant. 


\section{Background subtraction.}

Ambient measurements. Instrumental backgrounds we measured for one minute every hour during SOAS and SPiFFY. Backgrounds were performed by introducing purified air upstream of the inlet to the instrument. Many species exhibited a first-order decay in signal during the background measurement as a result of gas-wall partitioning equilibrium effects on tubing (Deming et al., 2019) leading to the instrument and on the surface of the ion-molecule reactor (Krechmer et al., 2016). These wall effects complicate measurement of a "true" instrumental background and methods employing short-duration $(<5$ s) background determination have been shown to be successful for plume-like sampling conditions (Lee et al., 2018). For the "long" backgrounds employed here we are likely over-estimating the background for species with sufficiently low vapor pressures. For the 10 second averaged data we take the final three signal points during the background measurement, average them, then subtract that value from the time series for a given species corresponding to that hour of measurement.

FIXCIT measurements. Two background experiments were performed to capture the method backgrounds for experiments involving $\mathrm{OH}$ oxidation of isoprene and $\alpha$-pinene under conditions of "low NO" or "high NO" during FIXCIT. Details about the blank experiments are provided in Nguyen et al (2014). To account for background, we take the signal from all species in the mass spectrum and subtract from it the signal acquired, after an equivalent amount of time, from the corresponding blank experiment (i.e. for the isoprene + OH "low NO" experiment that lasted five hours we subtract the corresponding signal after five hours from the blank OH "low NO" experiment). We recommend improving the understanding of how backgrounds impact organic acid production during chamber experiments by acquiring measurements of experiment-simulated backgrounds before and after an experiment involving a precursor in the future. The signal from species prior to injection of the hydrocarbon precursor was defined as the background for ozonolysis and the nitrate radical oxidation experiments.

Detection limit filtering. Following a previously published method (Liu et al., 2017), ion signals were determined to be quantifiable if the average ion signal was above the signal detection limit. For each file of 10 second data collected during the SOAS campaign, the signal for each high resolution identified species was averaged during a 30-minute time period in the middle of the file (i.e. 15 minutes from the start and 15 before the end of file collection) and was defined as the average signal for that file. A short three second period from the zero period that occurred during each file was also averaged for each HR species and that was defined as the background signal average. The detection limit for the averaged signal was then calculated by equation 1 :

$$
\left.D L_{\bar{S}}=\left(3 \sigma_{\text {back }}+S i g_{\text {back }}\right) x \sqrt{\frac{t_{\text {back }}}{t_{\text {signal }}}} \quad \text { (equation } 1\right)
$$

Where $\mathrm{DL}_{\mathrm{s}}$ is the average signal detection limit, $\sigma_{\text {back }}$ is the standard deviation of the signal during the background measurement, Sig $_{\text {back }}$ is the average signal during the background measurement, $t_{\text {back }}$ is the duration of the average for the background measurement and $t_{\text {signal }}$ is the duration of the average for measurement of the signal during ambient sampling.

Determination of clustered species in Acetate CIMS spectra. Manual peak assignment was performed on the mass spectra for FIXCIT. During FIXCIT the acetate CIMS was operated as to optimize the transmission of [acetate $+\mathrm{M}$ ] clusters. Operating the acetate CIMS in a "clustering" mode results in ambiguity when identifying deprotonated $\mathrm{M}^{-}$species from species clustered with acetate in the mass spectrum (Brophy and Farmer, 2016). A recent review (Wennberg et al., 2018) of isoprene oxidation chemistry was used to help identify potential species that most likely appeared as clusters with the acetate reagent ion in the mass spectrum. Identification of the isoprene and monoterpene oxidation product 
clusters was verified by observing the presence of the $[\mathrm{M}+\mathrm{I}]$ - clusters in the mass spectra acquired during the same experiments by the iodide reagent. Other species, such as $\mathrm{C}_{5} \mathrm{H}_{10} \mathrm{O}_{3}$ and $\mathrm{C}_{10} \mathrm{H}_{17} \mathrm{NO}_{5}$, were also verified by co-identification with the $\mathrm{CF}_{3} \mathrm{O}^{-} \mathrm{CIMS}$. Specific experiments were not performed during FIXCIT to determine if species identified as clusters with acetate in the mass spectrum were in fact clusters so if an elemental formula identified in the mass spectrum could feasibly be an acetate ion clustered with a neutral species than the peak was assigned as an acetate cluster. It was observed from the experiments that acetate clusters with appreciable sensitivity with organic nitrate species as well as peroxides. This chemical information was considered when assigning identities to peaks in the mass spectrum. Species filtering procedures described below were used to exclude potential fragments or clustered species from quantification.

Clustered species identified in the FIXCIT chamber study. A total of 15 isoprene and terpene were uniquely associated with the precursor oxidation and different from background signals.

\begin{tabular}{|c|c|c|c|c|c|}
\hline Precursor & $\begin{array}{l}\text { observed } \\
\text { formula }\end{array}$ & $\begin{array}{l}\mathbf{m} / \mathbf{z} \\
\text { (acetate }+ \\
\text { M) }\end{array}$ & Identification $^{\mathrm{a}}$ & $\begin{array}{l}\text { Experiment } \\
\text { observed }\end{array}$ & $\begin{array}{l}\text { Observed } \\
\text { at SOAS }\end{array}$ \\
\hline isoprene & $\mathrm{C}_{4} \mathrm{H}_{8} \mathrm{O}_{3} \cdot\left(\mathrm{C}_{2} \mathrm{H}_{3} \mathrm{O}_{2}\right)^{-}$ & 163.06 & $\begin{array}{l}\text { Dihydroxy } \\
\text { butanone/ } \mathrm{C}_{4} \\
\text { dihydroxycarbonyl }\end{array}$ & $\begin{array}{l}\text { Low NO } \\
\text { isoprene }\end{array}$ & yes \\
\hline isoprene & $\begin{array}{l}\mathrm{C}_{5} \mathrm{H}_{10} \mathrm{O}_{3} \\
\left(\mathrm{C}_{2} \mathrm{H}_{3} \mathrm{O}_{2}\right)^{-}\end{array}$ & 177.08 & IEPOX/ISOPOOH & $\begin{array}{l}\text { Low NO } \\
\text { isoprene }\end{array}$ & yes \\
\hline isoprene & $\begin{array}{l}\mathrm{C}_{5} \mathrm{H}_{12} \mathrm{O}_{4} \\
\left(\mathrm{C}_{2} \mathrm{H}_{3} \mathrm{O}_{2}\right)^{-}\end{array}$ & 195.09 & Pentaerythritol? & $\begin{array}{l}\text { Low NO } \\
\text { isoprene }\end{array}$ & yes \\
\hline isoprene & $\begin{array}{l}\mathrm{C}_{5} \mathrm{H}_{10} \mathrm{O}_{5} \\
\left(\mathrm{C}_{2} \mathrm{H}_{3} \mathrm{O}_{2}\right)^{-}\end{array}$ & 209.07 & $\mathrm{C}_{5} \mathrm{HOM}$ & $\begin{array}{l}\text { Low NO } \\
\text { isoprene }\end{array}$ & yes \\
\hline isoprene & $\mathrm{C}_{4} \mathrm{H}_{8} \mathrm{O}_{5} \cdot\left(\mathrm{C}_{2} \mathrm{H}_{3} \mathrm{O}_{2}\right)^{-}$ & 195.05 & $\mathrm{C}_{4} \mathrm{HOM}$ & $\begin{array}{l}\text { Low NO } \\
\text { isoprene }\end{array}$ & yes \\
\hline isoprene & $\begin{array}{l}\mathrm{C}_{4} \mathrm{H}_{7} \mathrm{NO}_{5} \cdot \\
\left(\mathrm{C}_{2} \mathrm{H}_{3} \mathrm{O}_{2}\right)^{-}\end{array}$ & 208.05 & $\begin{array}{l}\text { MVK/MACR } \\
\text { hydroxynitrate }\end{array}$ & $\begin{array}{l}\text { High NO } \\
\text { isoprene }\end{array}$ & yes \\
\hline Isoprene & $\begin{array}{l}\mathrm{C}_{5} \mathrm{H}_{11} \mathrm{NO}_{4} \cdot \\
\left(\mathrm{C}_{2} \mathrm{H}_{3} \mathrm{O}_{2}\right)^{-}\end{array}$ & 208.08 & $\begin{array}{l}\text { Unreported saturated } \\
\text { hydroxynitrate? }\end{array}$ & $\begin{array}{l}\text { High NO } \\
\text { isoprene }\end{array}$ & no \\
\hline isoprene & $\mathrm{C}_{4} \mathrm{H}_{8} \mathrm{O}_{6} \cdot\left(\mathrm{C}_{2} \mathrm{H}_{3} \mathrm{O}_{2}\right)^{-}$ & 211.05 & $\mathrm{C}_{4} \mathrm{HOM}$ & $\begin{array}{l}\text { High NO } \\
\text { isoprene }\end{array}$ & no \\
\hline isoprene & $\mathrm{CH}_{4} \mathrm{O}_{3} \cdot\left(\mathrm{C}_{2} \mathrm{H}_{3} \mathrm{O}_{2}\right)^{-}$ & 123.03 & sCI product? & $\begin{array}{l}\text { Ozone no } \\
\text { scavenger }\end{array}$ & no \\
\hline isoprene & $\mathrm{CH}_{4} \mathrm{O}_{4} \cdot\left(\mathrm{C}_{2} \mathrm{H}_{3} \mathrm{O}_{2}\right)^{-}$ & 139.05 & $\mathrm{sCI}$ product? & $\begin{array}{l}\text { Ozone no } \\
\text { scavenger }\end{array}$ & no \\
\hline isoprene & $\begin{array}{l}\mathrm{C}_{5} \mathrm{H}_{9} \mathrm{NO}_{5} \\
\left(\mathrm{C}_{2} \mathrm{H}_{3} \mathrm{O}_{2}\right)^{-}\end{array}$ & 222.06 & $\begin{array}{l}\text { Major isoprene }+\mathrm{NO}_{3} \\
\text { product prev. reported }\end{array}$ & $\begin{array}{l}\mathrm{NO}_{3} \text { and } \\
\text { formaldehyde }\end{array}$ & yes \\
\hline isoprene & $\begin{array}{l}\mathrm{C}_{5} \mathrm{H}_{9} \mathrm{NO}_{6} \cdot \\
\left(\mathrm{C}_{2} \mathrm{H}_{3} \mathrm{O}_{2}\right)^{-}\end{array}$ & 238.06 & $\mathrm{C}_{5}$ hydroxynitrate? & $\begin{array}{l}\mathrm{NO}_{3} \text { and } \\
\text { formaldehyde }\end{array}$ & yes \\
\hline isoprene & $\begin{array}{l}\mathrm{C}_{4} \mathrm{H}_{5} \mathrm{NO}_{7} \\
\left(\mathrm{C}_{2} \mathrm{H}_{3} \mathrm{O}_{2}\right)^{-}\end{array}$ & 238.02 & $\mathrm{C}_{4}$ hydroxynitrate? & $\begin{array}{l}\mathrm{NO}_{3} \text { and } \\
\text { formaldehyde }\end{array}$ & yes \\
\hline
\end{tabular}




\begin{tabular}{llllll} 
a-pinene & $\begin{array}{l}\mathrm{C}_{10} \mathrm{H}_{17} \mathrm{NO}_{5} \cdot \\
\left(\mathrm{C}_{2} \mathrm{H}_{3} \mathrm{O}_{2}\right)^{-}\end{array}$ & 290.13 & $\begin{array}{l}\text { pinene } \\
\text { nitrooxyhydroperoxide }\end{array}$ & $\begin{array}{l}\text { high } \mathrm{NO} \text { a- } \\
\text { pinene }+\mathrm{OH}\end{array}$ & yes \\
a-pinene & $\begin{array}{l}\mathrm{C}_{9} \mathrm{H}_{13} \mathrm{O}_{6} \cdot \\
\left(\mathrm{C}_{2} \mathrm{H}_{3} \mathrm{O}_{2}\right)^{-}\end{array}$ & 276.06 & $\mathrm{C}_{9} \mathrm{HOM}$ & $\begin{array}{l}\text { high NO a- } \\
\text { pinene }+\mathrm{OH}\end{array}$ & no \\
\hline
\end{tabular}

Table S2. Species identified as clusters with the acetate reagent from the FIXCIT experiment.

81 ahighly oxidized molecule (HOM)

82 Clustered species identified at SOAS. A total of 53 compounds in the mass spectrum were identified as 83 clusters with acetate. Previous studies have observed that organic peroxides and carboxylic acids cluster 84 favorably with acetate (Brophy and Farmer, 2016; Budisulistiorini et al., 2015; Inomata and Hirokawa, 85 2016), but we also observe favorable clustering with organonitrate compounds. The identity of many of 86 the species identified as clusters with the acetate reagent were validated by confirming their presence in 87 spectra collected using the iodide reagent during the campaign.

\begin{tabular}{|c|c|c|c|c|}
\hline Precursor & $\begin{array}{l}\text { observed } \\
\text { formula }\end{array}$ & $\begin{array}{l}\mathrm{m} / \mathrm{z} \text { (acetate } \\
+\mathrm{M})\end{array}$ & Identification $^{\mathrm{a}}$ & $\begin{array}{l}\text { Observed } \\
\text { with iodide }\end{array}$ \\
\hline & $\mathrm{C}_{2} \mathrm{H}_{6} \mathrm{O}_{4} \cdot\left(\mathrm{C}_{2} \mathrm{H}_{3} \mathrm{O}_{2}\right)^{-}$ & 153.04 & polyol? & yes \\
\hline isoprene & $\mathrm{C}_{5} \mathrm{H}_{9} \mathrm{O}_{2} \cdot\left(\mathrm{C}_{2} \mathrm{H}_{3} \mathrm{O}_{2}\right)^{-}$ & 160.07 & Isoprene hydroxy carbonyl & no \\
\hline \multirow[t]{4}{*}{ isoprene } & $\mathrm{C}_{4} \mathrm{H}_{6} \mathrm{O}_{3} \cdot\left(\mathrm{C}_{2} \mathrm{H}_{3} \mathrm{O}_{2}\right)^{-}$ & 161.05 & methacrylic acid epoxide & yes \\
\hline & $\mathrm{C}_{4} \mathrm{H}_{7} \mathrm{O}_{3} \cdot\left(\mathrm{C}_{2} \mathrm{H}_{3} \mathrm{O}_{2}\right)^{-}$ & 162.04 & & yes \\
\hline & $\mathrm{C}_{4} \mathrm{H}_{8} \mathrm{O}_{3} \cdot\left(\mathrm{C}_{2} \mathrm{H}_{3} \mathrm{O}_{2}\right)^{-}$ & 163.06 & hydroxybutyric acid? & yes \\
\hline & $\mathrm{C}_{3} \mathrm{H}_{4} \mathrm{O}_{4} \cdot\left(\mathrm{C}_{2} \mathrm{H}_{3} \mathrm{O}_{2}\right)^{-}$ & 163.02 & malonic acid? & yes \\
\hline \multirow[t]{2}{*}{ isoprene } & $\mathrm{C}_{5} \mathrm{H}_{8} \mathrm{O}_{3} \cdot\left(\mathrm{C}_{2} \mathrm{H}_{3} \mathrm{O}_{2}\right)^{-}$ & 175.06 & HPALD & yes \\
\hline & $\mathrm{C}_{4} \mathrm{H}_{4} \mathrm{O}_{4} \cdot\left(\mathrm{C}_{2} \mathrm{H}_{3} \mathrm{O}_{2}\right)^{-}$ & 175.02 & maleic acid? & yes \\
\hline isoprene & $\mathrm{C}_{5} \mathrm{H}_{10} \mathrm{O}_{3} \cdot\left(\mathrm{C}_{2} \mathrm{H}_{3} \mathrm{O}_{2}\right)^{-}$ & 177.08 & IEPOX/ISOPOOH & yes \\
\hline isoprene & $\mathrm{C}_{4} \mathrm{H}_{6} \mathrm{O}_{4} \cdot\left(\mathrm{C}_{2} \mathrm{H}_{3} \mathrm{O}_{2}\right)^{-}$ & 177.04 & ISOPOOH $+\mathrm{OH}$ product & yes \\
\hline \multirow[t]{4}{*}{ isoprene } & $\mathrm{C}_{4} \mathrm{H}_{8} \mathrm{O}_{4} \cdot\left(\mathrm{C}_{2} \mathrm{H}_{3} \mathrm{O}_{2}\right)^{-}$ & 179.06 & 2-methylglyceric acid & yes \\
\hline & $\mathrm{C}_{5} \mathrm{H}_{12} \mathrm{O}_{3} \cdot\left(\mathrm{C}_{2} \mathrm{H}_{3} \mathrm{O}_{2}\right)^{-}$ & 179.09 & & no \\
\hline & $\mathrm{C}_{5} \mathrm{H}_{8} \mathrm{O}_{4} \cdot\left(\mathrm{C}_{2} \mathrm{H}_{3} \mathrm{O}_{2}\right)^{-}$ & 191.06 & glutaric acid? & yes \\
\hline & $\mathrm{C}_{4} \mathrm{H}_{4} \mathrm{O}_{5} \cdot\left(\mathrm{C}_{2} \mathrm{H}_{3} \mathrm{O}_{2}\right)^{-}$ & 191.02 & diacid? & yes \\
\hline \multirow[t]{4}{*}{ isoprene } & $\mathrm{C}_{5} \mathrm{H}_{10} \mathrm{O}_{4} \cdot\left(\mathrm{C}_{2} \mathrm{H}_{3} \mathrm{O}_{2}\right)^{-}$ & 193.07 & ISOPOOH + OH product & yes \\
\hline & $\mathrm{C}_{4} \mathrm{H}_{6} \mathrm{O}_{5} \cdot\left(\mathrm{C}_{2} \mathrm{H}_{3} \mathrm{O}_{2}\right)^{-}$ & 193.04 & diacid? & yes \\
\hline & $\mathrm{C}_{5} \mathrm{H}_{12} \mathrm{O}_{4} \cdot\left(\mathrm{C}_{2} \mathrm{H}_{3} \mathrm{O}_{2}\right)^{-}$ & 195.09 & polyol? & yes \\
\hline & $\mathrm{C}_{4} \mathrm{H}_{8} \mathrm{O}_{5} \cdot\left(\mathrm{C}_{2} \mathrm{H}_{3} \mathrm{O}_{2}\right)^{-}$ & 195.05 & hydroxyacid? & yes \\
\hline
\end{tabular}




\begin{tabular}{|c|c|c|c|c|}
\hline \multirow[t]{10}{*}{ isoprene } & $\mathrm{C}_{5} \mathrm{H}_{9} \mathrm{NO}_{4} \cdot\left(\mathrm{C}_{2} \mathrm{H}_{3} \mathrm{O}_{2}\right)^{-}$ & 206.07 & $\begin{array}{l}1^{\text {st }} \text { generation isoprene } \\
\text { nitrate }\end{array}$ & yes \\
\hline & $\mathrm{C}_{4} \mathrm{H}_{5} \mathrm{NO}_{5} \cdot\left(\mathrm{C}_{2} \mathrm{H}_{3} \mathrm{O}_{2}\right)^{-}$ & 206.03 & Isoprene nitrate? & yes \\
\hline & $\mathrm{C}_{5} \mathrm{H}_{8} \mathrm{O}_{5} \cdot\left(\mathrm{C}_{2} \mathrm{H}_{3} \mathrm{O}_{2}\right)^{-}$ & 207.05 & diacid? & yes \\
\hline & $\mathrm{C}_{4} \mathrm{H}_{7} \mathrm{NO}_{5} \cdot\left(\mathrm{C}_{2} \mathrm{H}_{3} \mathrm{O}_{2}\right)^{-}$ & 208.05 & Isoprene nitrate? & yes \\
\hline & $\mathrm{C}_{5} \mathrm{H}_{10} \mathrm{O}_{5} \cdot\left(\mathrm{C}_{2} \mathrm{H}_{3} \mathrm{O}_{2}\right)^{-}$ & 209.07 & $\mathrm{C}_{5}$ isoprene $\mathrm{HOM}$ & yes \\
\hline & $\mathrm{C}_{4} \mathrm{H}_{6} \mathrm{O}_{4} \mathrm{~S} \cdot\left(\mathrm{C}_{2} \mathrm{H}_{3} \mathrm{O}_{2}\right)^{-}$ & 209.01 & $\mathrm{C}_{4}$ organosulfate? & yes \\
\hline & $\mathrm{C}_{7} \mathrm{H}_{12} \mathrm{O}_{4} \cdot\left(\mathrm{C}_{2} \mathrm{H}_{3} \mathrm{O}_{2}\right)^{-}$ & 219.09 & diacid? & yes \\
\hline & $\mathrm{C}_{5} \mathrm{H}_{9} \mathrm{NO}_{5} \cdot\left(\mathrm{C}_{2} \mathrm{H}_{3} \mathrm{O}_{2}\right)^{-}$ & 222.06 & Isoprene nitrate? & yes \\
\hline & $\mathrm{C}_{5} \mathrm{H}_{11} \mathrm{NO}_{5} \cdot\left(\mathrm{C}_{2} \mathrm{H}_{3} \mathrm{O}_{2}\right)^{-}$ & 224.08 & Isoprene hydroxy nitrate? & yes \\
\hline & $\mathrm{C}_{5} \mathrm{H}_{9} \mathrm{O}_{6} \cdot\left(\mathrm{C}_{2} \mathrm{H}_{3} \mathrm{O}_{2}\right)^{-}$ & 224.05 & & yes \\
\hline isoprene & $\mathrm{C}_{5} \mathrm{H}_{10} \mathrm{O}_{6} \cdot\left(\mathrm{C}_{2} \mathrm{H}_{3} \mathrm{O}_{2}\right)^{-}$ & 225.06 & $\mathrm{ISOPOOH}+\mathrm{OH}$ product & yes \\
\hline \multirow[t]{5}{*}{ isoprene } & $\mathrm{C}_{5} \mathrm{H}_{9} \mathrm{NO}_{6} \cdot\left(\mathrm{C}_{2} \mathrm{H}_{3} \mathrm{O}_{2}\right)^{-}$ & 238.06 & $\mathrm{C}_{5}$ hydroxynitrate? & yes \\
\hline & $\mathrm{C}_{4} \mathrm{H}_{5} \mathrm{NO}_{7} \cdot\left(\mathrm{C}_{2} \mathrm{H}_{3} \mathrm{O}_{2}\right)^{-}$ & 238.02 & $\mathrm{C}_{4}$ hydroxynitrate? & yes \\
\hline & $\mathrm{C}_{4} \mathrm{H}_{6} \mathrm{NO}_{7} \cdot\left(\mathrm{C}_{2} \mathrm{H}_{3} \mathrm{O}_{2}\right)^{-}$ & 239.03 & & yes \\
\hline & $\mathrm{C}_{5} \mathrm{H}_{10} \mathrm{NO}_{6} \cdot\left(\mathrm{C}_{2} \mathrm{H}_{3} \mathrm{O}_{2}\right)^{-}$ & 239.06 & & no \\
\hline & $\mathrm{C}_{5} \mathrm{H}_{9} \mathrm{O}_{7} \cdot\left(\mathrm{C}_{2} \mathrm{H}_{3} \mathrm{O}_{2}\right)^{-}$ & 240.05 & $\mathrm{C}_{5} \mathrm{HOM}$ & yes \\
\hline \multirow[t]{12}{*}{ terpene } & $\mathrm{C}_{10} \mathrm{H}_{16} \mathrm{O}_{3} \cdot\left(\mathrm{C}_{2} \mathrm{H}_{3} \mathrm{O}_{2}\right)^{-}$ & 243.12 & $\begin{array}{l}\text { pinonic acid or related } \\
\text { isomer }\end{array}$ & yes \\
\hline & $\mathrm{C}_{9} \mathrm{H}_{12} \mathrm{O}_{4} \cdot\left(\mathrm{C}_{2} \mathrm{H}_{3} \mathrm{O}_{2}\right)^{-}$ & 243.09 & $\begin{array}{l}\text { Terpene oxidation } \\
\text { product? }\end{array}$ & yes \\
\hline & $\mathrm{C}_{9} \mathrm{H}_{14} \mathrm{O}_{4} \cdot\left(\mathrm{C}_{2} \mathrm{H}_{3} \mathrm{O}_{2}\right)^{-}$ & 245.1 & $\begin{array}{l}\text { Terpene oxidation } \\
\text { product? }\end{array}$ & yes \\
\hline & $\mathrm{C}_{6} \mathrm{H}_{6} \mathrm{O}_{7} \cdot\left(\mathrm{C}_{2} \mathrm{H}_{3} \mathrm{O}_{2}\right)^{-}$ & 249.03 & $\mathrm{C}_{6} \mathrm{HOM}$ & yes \\
\hline & $\mathrm{C}_{9} \mathrm{H}_{18} \mathrm{O}_{4} \cdot\left(\mathrm{C}_{2} \mathrm{H}_{3} \mathrm{O}_{2}\right)^{-}$ & 249.13 & & yes \\
\hline & $\mathrm{C}_{9} \mathrm{H}_{10} \mathrm{O}_{5} \cdot\left(\mathrm{C}_{2} \mathrm{H}_{3} \mathrm{O}_{2}\right)^{-}$ & 257.07 & $\begin{array}{l}\text { Terpene oxidation } \\
\text { product? }\end{array}$ & yes \\
\hline & $\mathrm{C}_{9} \mathrm{H}_{14} \mathrm{NO}_{4} \cdot\left(\mathrm{C}_{2} \mathrm{H}_{3} \mathrm{O}_{2}\right)^{-}$ & 259.11 & Terpene nitrate? & yes \\
\hline & $\mathrm{C}_{8} \mathrm{H}_{8} \mathrm{O}_{6} \cdot\left(\mathrm{C}_{2} \mathrm{H}_{3} \mathrm{O}_{2}\right)^{-}$ & 259.05 & $\mathrm{C}_{8} \mathrm{HOM}$ & yes \\
\hline & $\mathrm{C}_{7} \mathrm{H}_{6} \mathrm{O}_{7} \cdot\left(\mathrm{C}_{2} \mathrm{H}_{3} \mathrm{O}_{2}\right)^{-}$ & 261.03 & $\mathrm{C}_{7} \mathrm{HOM}$ & yes \\
\hline & $\mathrm{C}_{9} \mathrm{H}_{16} \mathrm{O}_{5} \cdot\left(\mathrm{C}_{2} \mathrm{H}_{3} \mathrm{O}_{2}\right)^{-}$ & 263.11 & $\begin{array}{l}\text { Terpene oxidation } \\
\text { product? }\end{array}$ & yes \\
\hline & $\mathrm{C}_{9} \mathrm{H}_{6} \mathrm{O}_{9} \cdot\left(\mathrm{C}_{2} \mathrm{H}_{3} \mathrm{O}_{2}\right)^{-}$ & 269.03 & & yes \\
\hline & $\mathrm{C}_{5} \mathrm{H}_{10} \mathrm{O}_{9} \cdot\left(\mathrm{C}_{2} \mathrm{H}_{3} \mathrm{O}_{2}\right)^{-}$ & 273.05 & $\begin{array}{l}\mathrm{C}_{5} \text { isoprene oxidation } \\
\mathrm{HOM}\end{array}$ & yes \\
\hline
\end{tabular}




\begin{tabular}{|c|c|c|c|c|}
\hline \multirow{7}{*}{ a-pinene } & $\mathrm{C}_{10} \mathrm{H}_{14} \mathrm{O}_{5} \cdot\left(\mathrm{C}_{2} \mathrm{H}_{3} \mathrm{O}_{2}\right)^{-}$ & 273.10 & $\begin{array}{l}\text { Terpene oxidation } \\
\text { product? }\end{array}$ & yes \\
\hline & $\mathrm{C}_{10} \mathrm{H}_{16} \mathrm{O}_{5} \cdot\left(\mathrm{C}_{2} \mathrm{H}_{3} \mathrm{O}_{2}\right)^{-}$ & 275.11 & $\begin{array}{l}\text { Terpene oxidation } \\
\text { product? }\end{array}$ & yes \\
\hline & $\mathrm{C}_{10} \mathrm{H}_{17} \mathrm{NO}_{5} \cdot\left(\mathrm{C}_{2} \mathrm{H}_{3} \mathrm{O}_{2}\right)^{-}$ & 290.13 & $\begin{array}{l}\text { pinene } \\
\text { nitrooxyhydroperoxide }\end{array}$ & no \\
\hline & $\mathrm{C}_{8} \mathrm{H}_{11} \mathrm{NO}_{7} \cdot\left(\mathrm{C}_{2} \mathrm{H}_{3} \mathrm{O}_{2}\right)^{-}$ & 292.07 & Terpene nitrate? & no \\
\hline & $\mathrm{C}_{9} \mathrm{H}_{15} \mathrm{NO}_{6} \cdot\left(\mathrm{C}_{2} \mathrm{H}_{3} \mathrm{O}_{2}\right)^{-}$ & 292.10 & Terpene nitrate? & yes \\
\hline & $\mathrm{C}_{10} \mathrm{H}_{19} \mathrm{NO}_{5} \cdot\left(\mathrm{C}_{2} \mathrm{H}_{3} \mathrm{O}_{2}\right)^{-}$ & 292.14 & Terpene nitrate? & yes \\
\hline & $\mathrm{C}_{10} \mathrm{H}_{15} \mathrm{NO}_{7} \cdot\left(\mathrm{C}_{2} \mathrm{H}_{3} \mathrm{O}_{2}\right)^{-}$ & 320.10 & Terpene nitrate? & yes \\
\hline
\end{tabular}

Table S3. Species identified as clusters with the acetate reagent observed during SOAS.

aSpecies identifications marked with "?" indicate significant uncertainty. Assignment of identification based on consideration of selectivity towards clustering, likelihood of appearing in the atmosphere, and/or informed from FIXCIT experiments or published literature.

Common measurement artifacts observed using acetate CIMS. Listed below (Table S4) are common artifacts observed in our field measurements using acetate CIMS. Depending on the "clustering" regime the mass spectrometer is configured to operate under some artifacts are going to be less relevant.

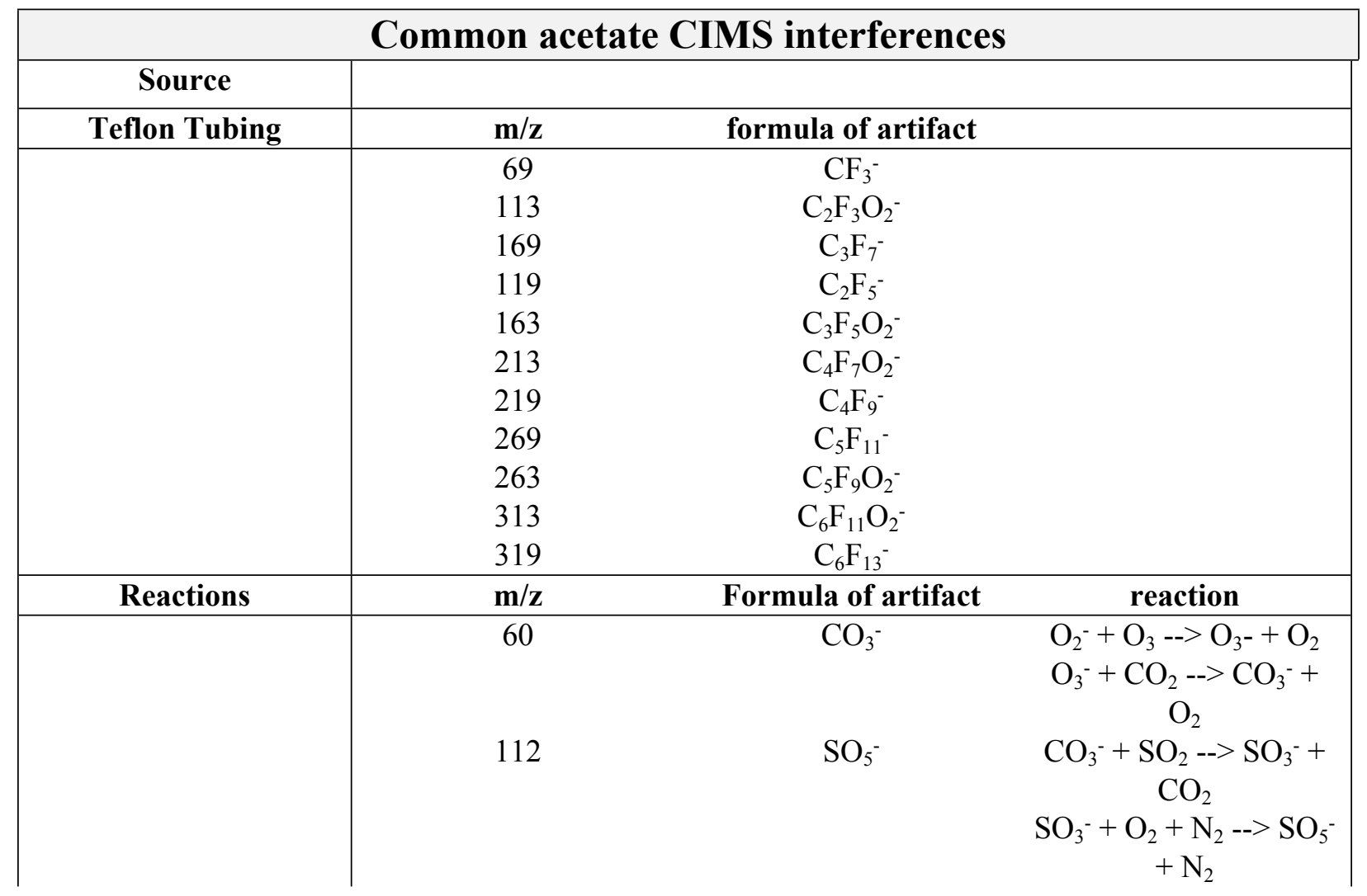




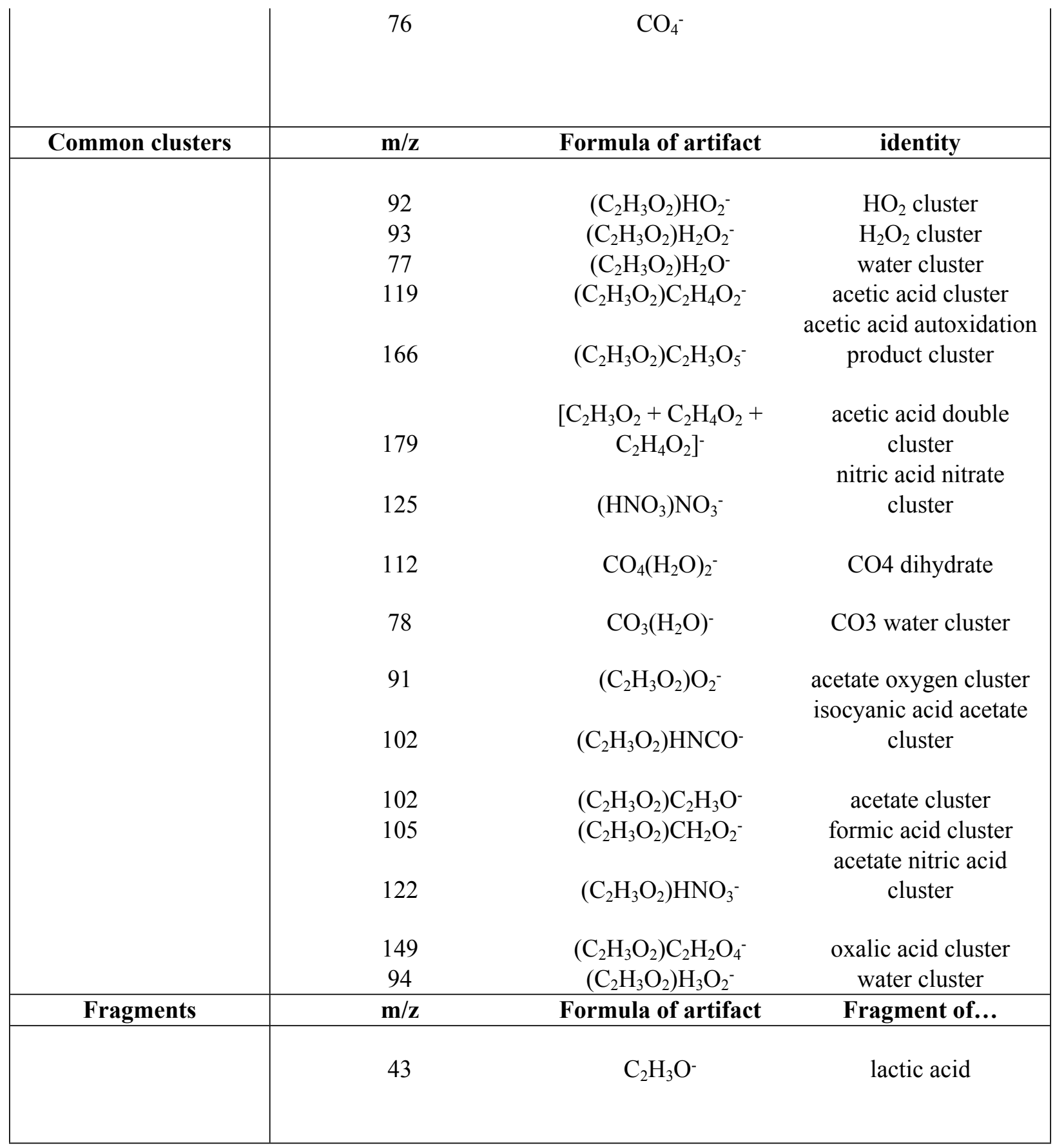

Table S4. Common measurement artifacts observed in acetate CIMS mass spectrum.

Comparison of parameterized-determined mixing ratios with hourly online calibration mixing ratios. Figure S1 shows a comparison between mixing ratios estimated from the Lui et al. (2017) method described in section S4 (estimated), and mixing ratios calculated from hourly online calibrations during the field campaign (measured). The slopes resulting from linear fits to the two sets of data suggest that the estimated mixing ratios provided in this current study likely underestimate "true" mixing ratios from anywhere between $15-70 \%$. The four acids compared here represent a small subset of the organic acid populations measured from both SOAS and SPiFFY and thus the conclusions drawn from this comparison are limited. 


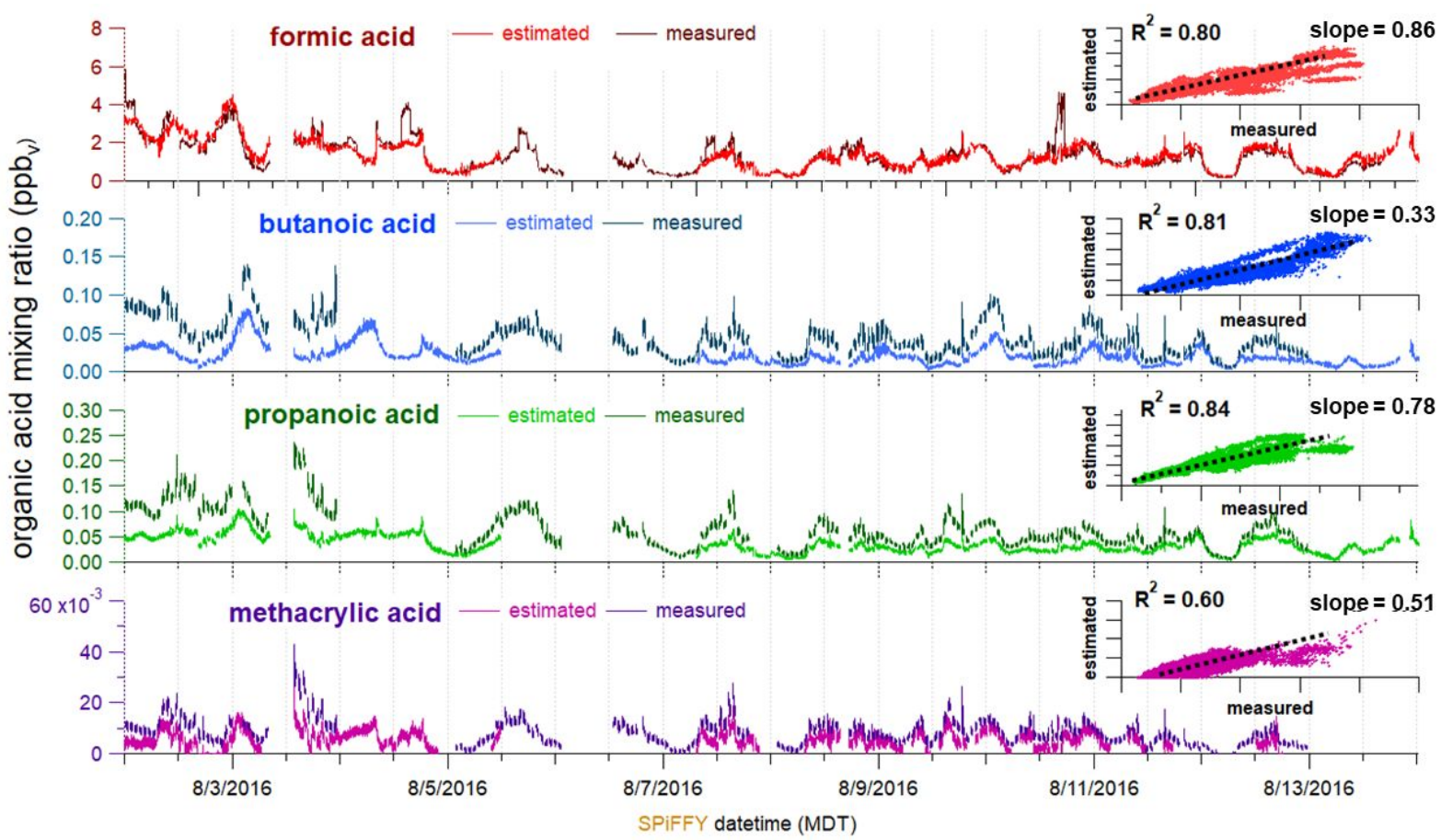

Figure S1. Comparison of measured (i.e., calculated from sensitivities from on-line hourly calibrations) and estimated (i.e., calculated from the sensitivity parameterization) mixing ratios for four organic acids during SPiFFY.

3. Spectra with speciation from FIXCIT. Figures S2-S8 show average mass spectra for each experiment listed in Table S1. Shown in red is total ion signal from the experiment. The black trace is the average mass spectrum from the background and the green inset figure shows the difference between the average mass spectrum during the experiment (signal) and the background. Many species were not confidently identified in the mass spectrum likely due to clustering processes that were not completely understood. 


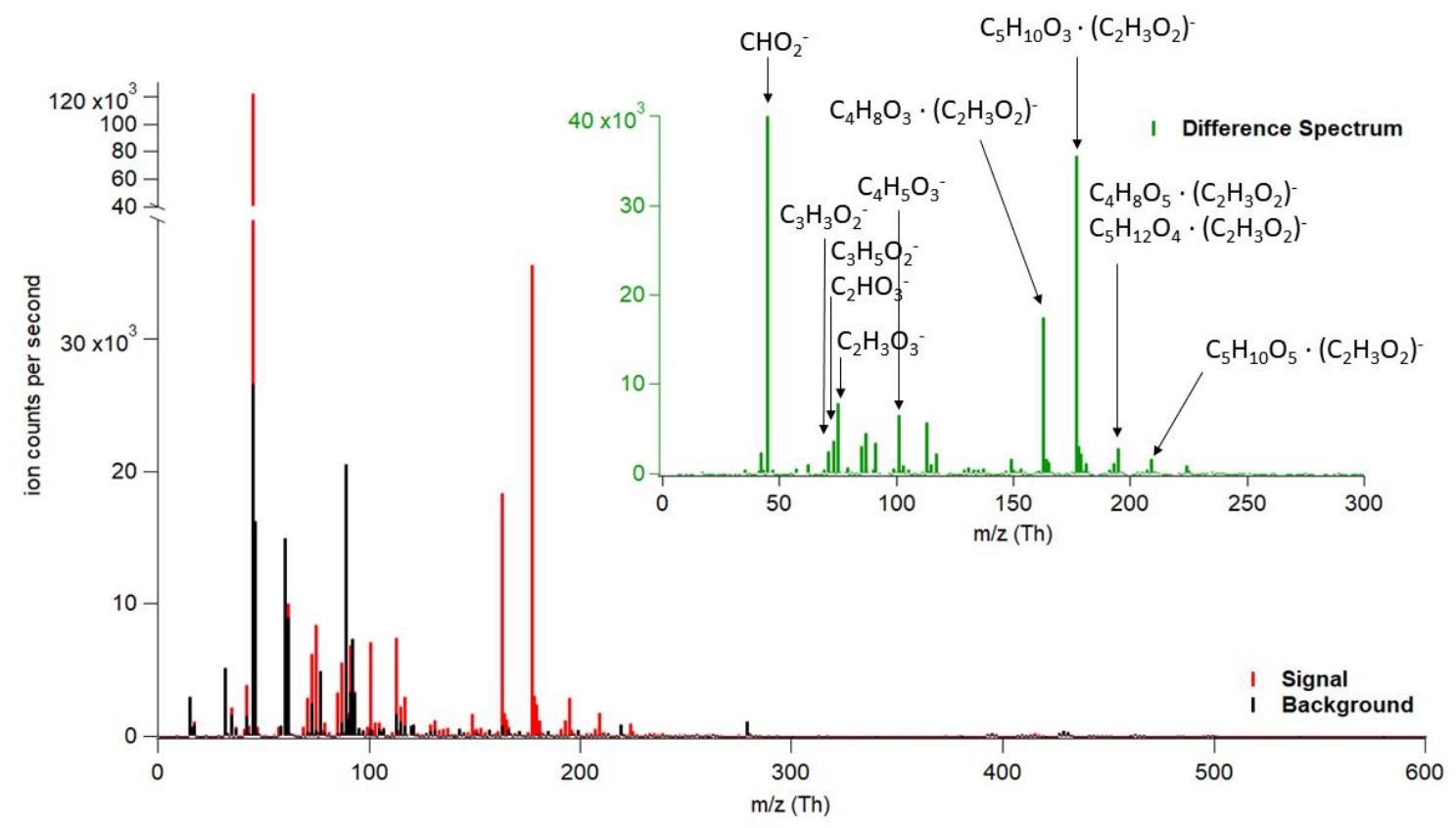

118

119 Figure S2. Average mass spectra from "low NO" isoprene $+\mathrm{OH}$ experiment.

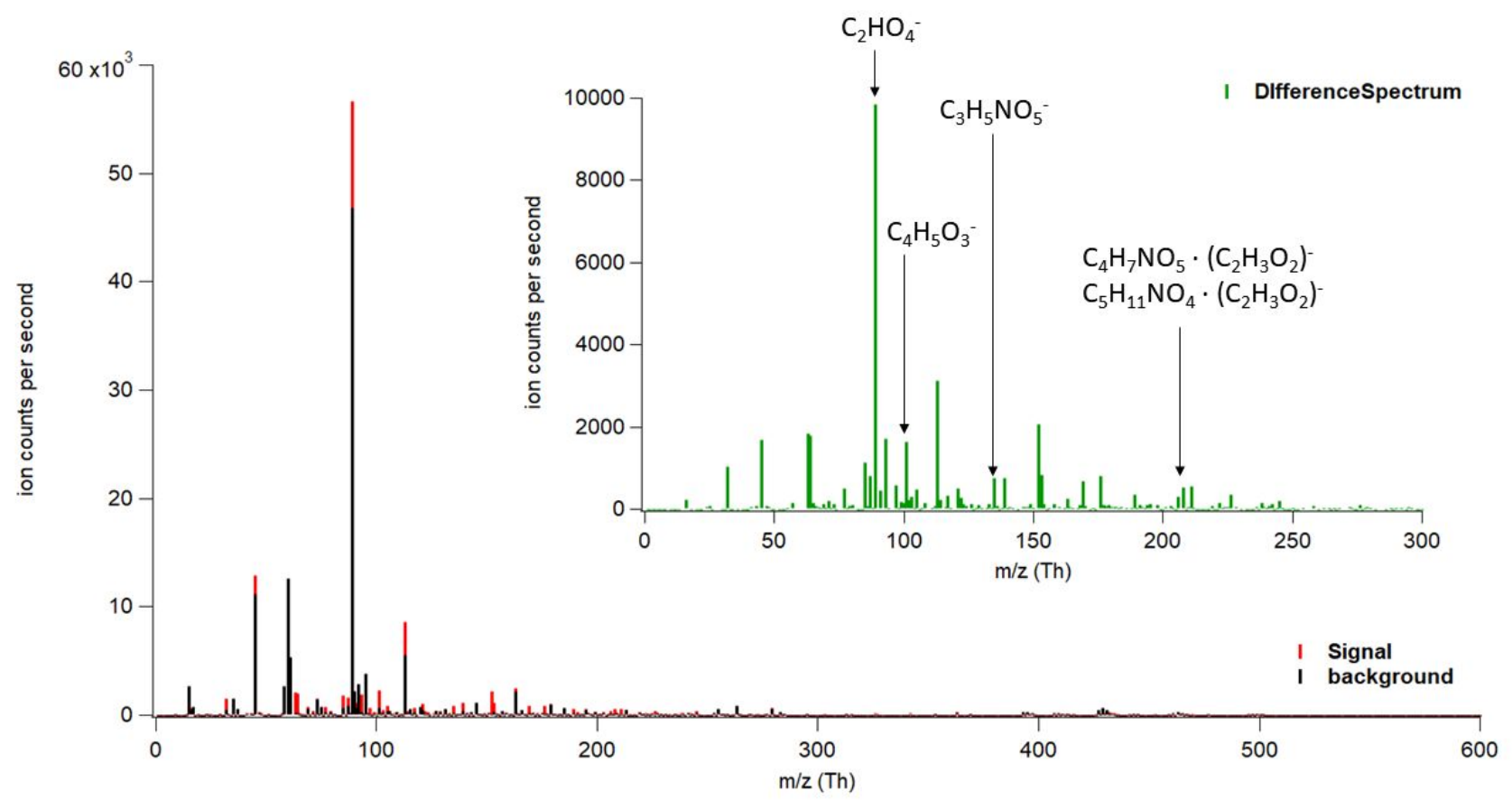

120

121

Figure S3. Average mass spectra from "high NO" isoprene + OH experiment. 


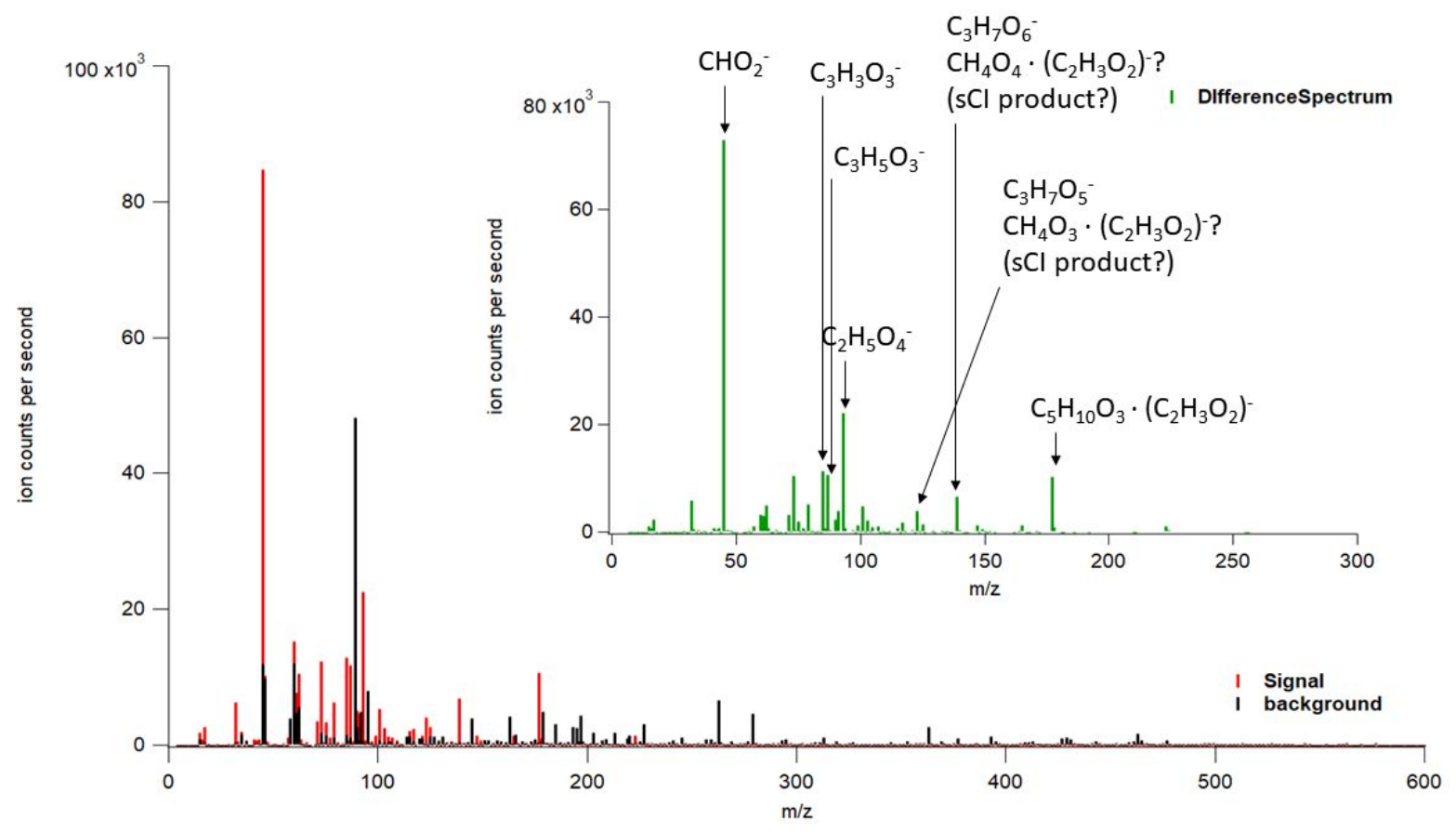

122

123 Figure $\mathbf{S 4}$. Average mass spectra from $\mathrm{O}_{3}+$ isoprene (no scavenger) experiment. Clustering with species tentatively 124 identified as stabilized Criegee intermediate oxidation products $(\mathrm{sCI})$ are shown.

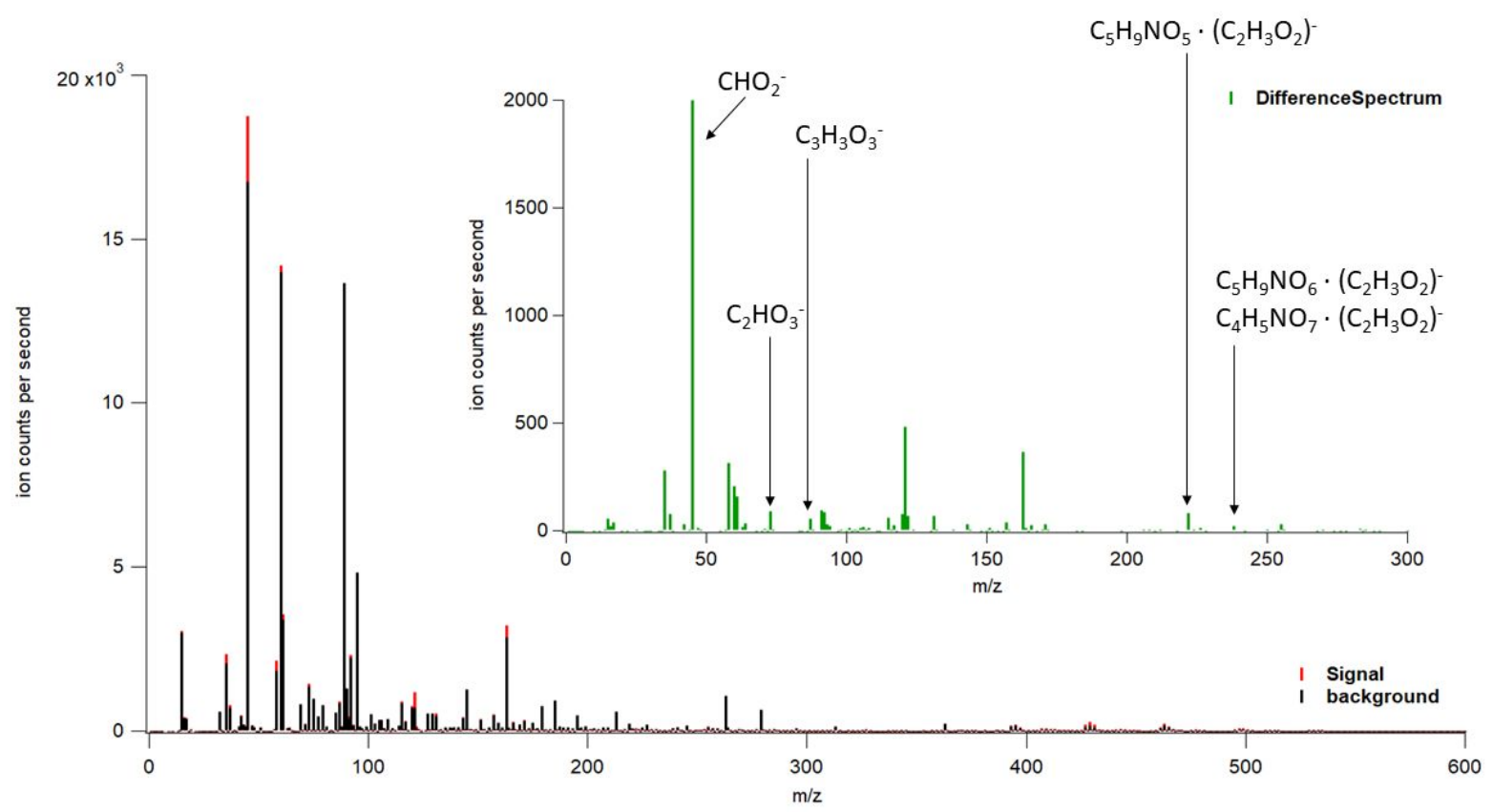

125

126 Figure S5. Average mass spectra from isoprene $+\mathrm{NO}_{3}$ experiment. 


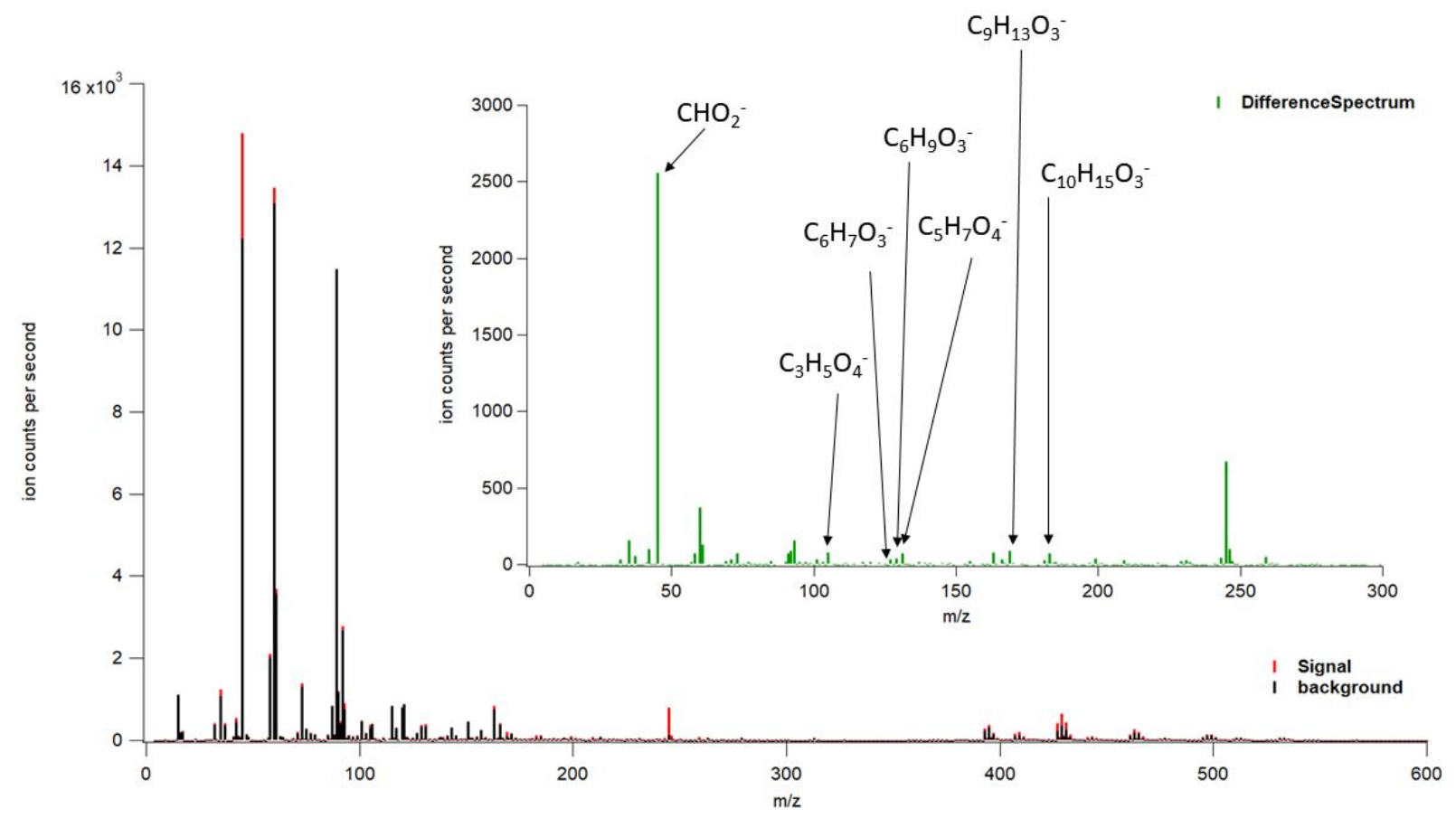

127

128 Figure S6. Average mass spectra from $\alpha$-pinene $+\mathrm{OH}$ "low-NO" experiment.

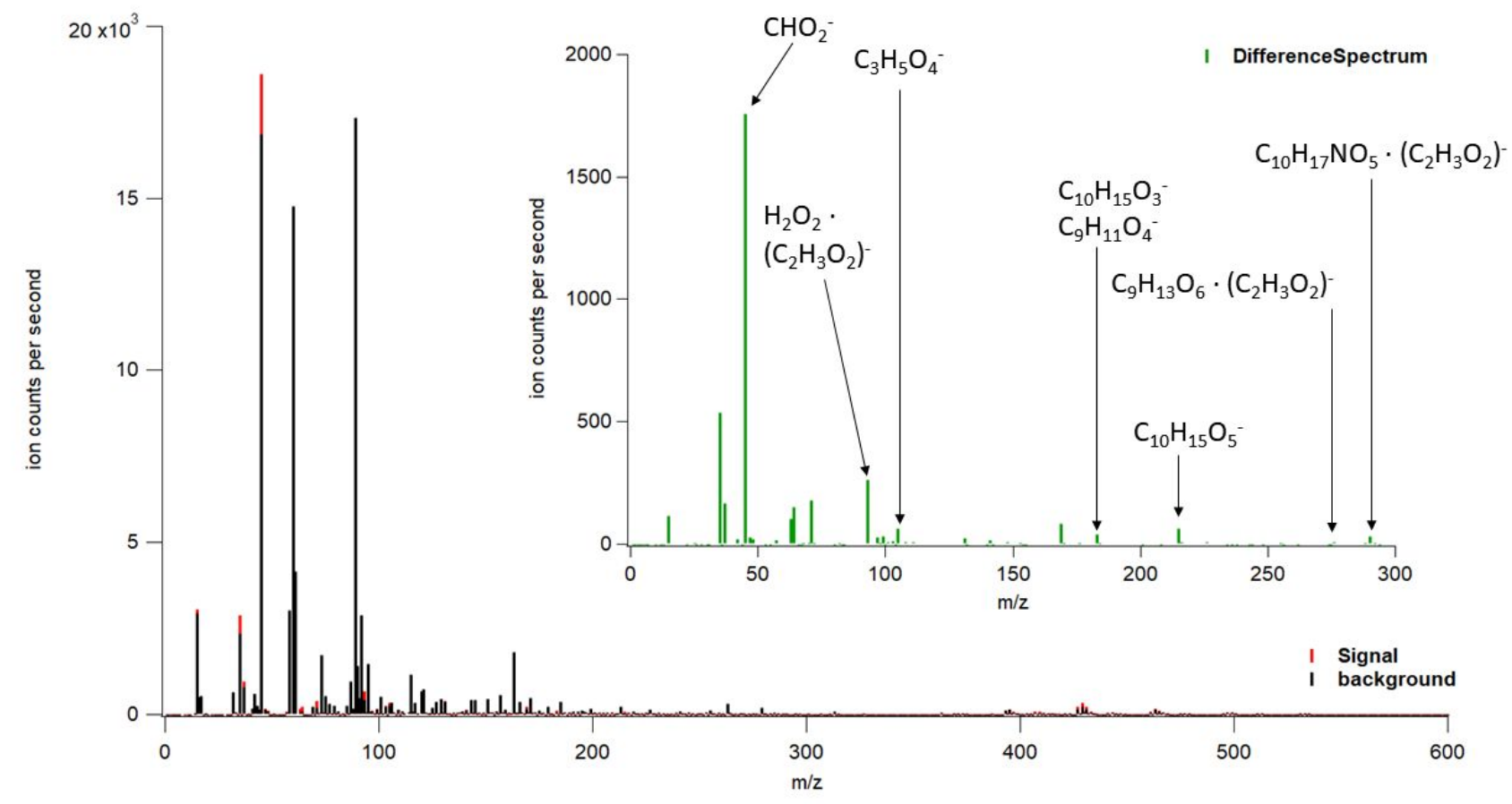

130 Figure S7. Average mass spectra from $\alpha$-pinene + OH "high NO" experiment. 


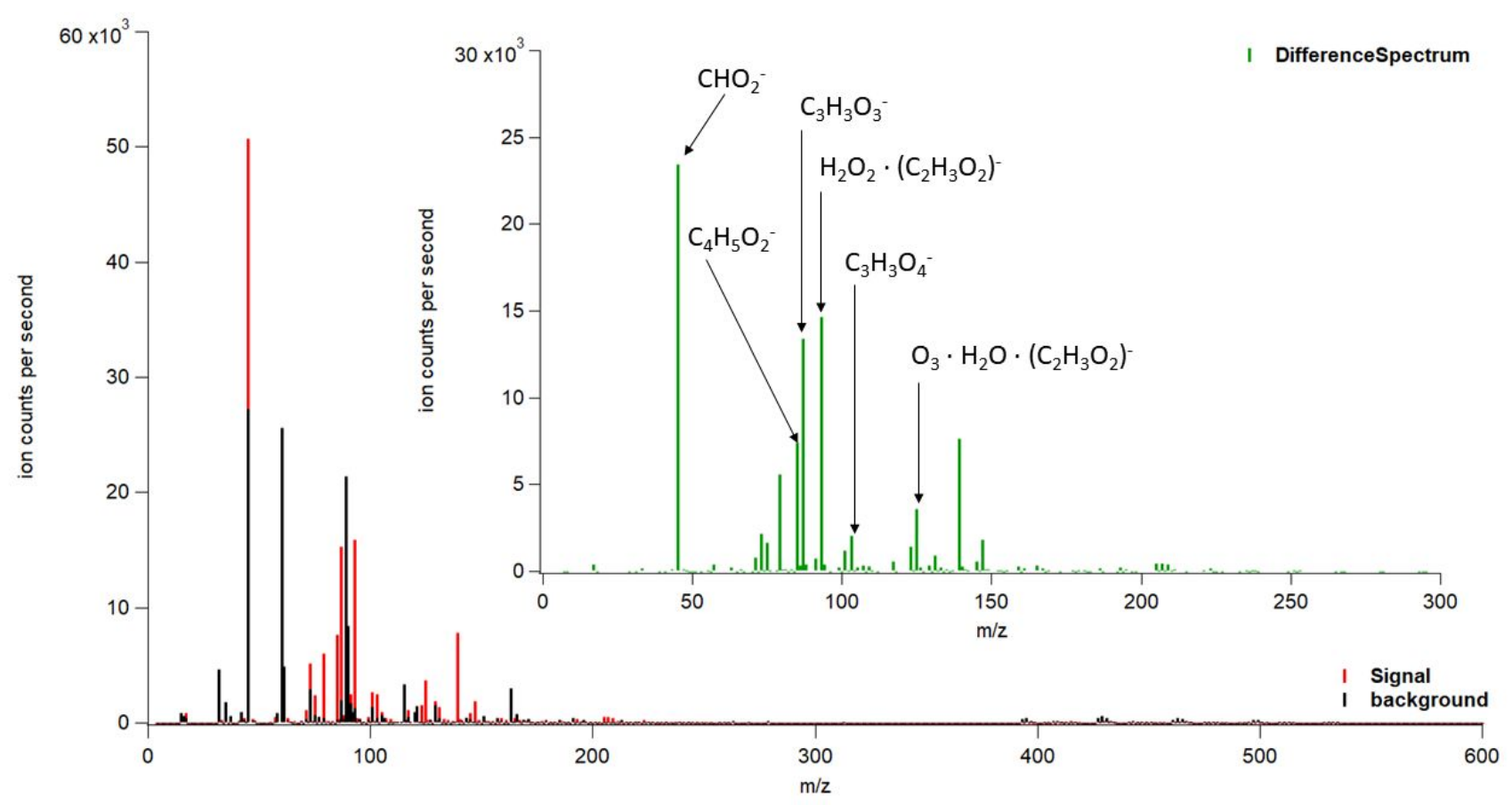

131

132

133

Figure S8. Average mass spectra from Isoprene $+\mathrm{O}_{3}$ (cyclohexane scavenger) experiment.

\section{Bulk quantification of the mass spectrum}

Parameterization of sensitivity and calibrations for acetate CIMS. A previously published (Liu et al., 2017) parameterization of sensitivity as a function of average carbon oxidation state (OSc) and carbon number was investigated and employed for quantification of organic acids in this study. Measured sensitivities were used in place of parameterized sensitivities when possible. A series of heated liquid injection calibrations (Murschell et al., 2017) were performed and sensitivities were measured for a wide variety of organic acids with different additional functional groups such as hydroxy, carbonyl and aromatic moieties. Liquid calibrant solutions were prepared in HPLC grade methanol and sonicated to ensure mixing. Injections of analytes were on the order of $10^{13}-10^{14}$ total molecules injected. A constant $10 \mu \mathrm{L}$ injection volume was used for all calibrations and was applied to a quartz filter enclosed in a PFA injection apparatus. Heating was applied with a heat gun over the PFA injection apparatus to ensure liquid analyte evaporation. When possible injections of calibrants were compared to permeation tube calibration sources and compared well. Calibrants that did not have permeation tube sources for comparison generally were in the condensed phase at room temperature and thus had corresponding low volatilities. Prolonged heating was necessary to get the lower volatility calibrants into the instrument. Previous studies have observed significant thermal decomposition of carboxylic acids when heated (Lopez-Hilfiker et al., 2014; Stark et al., 2017). Analysis of expected decarboxylation or dehydration products of the parent carboxylic acid suggest that thermal decomposition did not play a major role in determining signal intensity during the calibrations however this influence cannot be ruled out, so the sensitivities of the lower volatility compounds (i.e., pinonic, myristic and palmitic acids) measured here may represent a lower bound. 
Calibrations were performed under "declustered" and "clustered" ion transmission regimes to capture the effects of instrument operating conditions on sensitivity for the SPiFFY and SOAS/FIXCIT campaigns, respectively. The campaign averaged ratio of the reagent self-cluster $\left(\left[\mathrm{C}_{2} \mathrm{H}_{3} \mathrm{O}_{2}{ }^{-}+\mathrm{C}_{2} \mathrm{H}_{4} \mathrm{O}_{2}\right] ; \mathrm{m} / \mathrm{z} 119.03\right.$; acetate cluster) signal to the reagent $\left(\mathrm{C}_{2} \mathrm{H}_{3} \mathrm{O}_{2}^{-} ; \mathrm{m} / \mathrm{z}\right.$ 59.01; acetate) signal was used to determine if the voltage settings were configured such that the mass spectra would reflect "clustered' (i.e. high acetate cluster to acetate ratio) or "declustered" settings (i.e. low acetate cluster to acetate cluster ratio). It was demonstrated by Brophy and Farmer (2016) that tuning of the ion optics in the instrument can result in transmission where collisions are preferentially favored or limited resulting in mass spectra that contain either deprotonated species or clusters, respectively. The ratio of the signal of the acetate cluster to acetate should be the best indicator of the electric fields established in the ion optics under a particular set of voltage settings. Here we define "declustered" settings as ion optic voltage settings that produce an acetate cluster to acetate ratio of 0.004 and "clustered" as settings that produce a ratio of 0.04 (the ratio observed at SOAS was 0.02).

Using the relationship between sensitivity and extraction frequency-combined with the relative sensitivities observed under different voltage settings - the following equation was derived to convert sensitivities measured in lab to sensitivities that theoretically would have been observed at SOAS:

$$
\text { SOAS sensitivities } \left.=\frac{\text { Lab sensitiviites } x 0.716}{0.444} \quad \text { (equation } 2\right)
$$

The value of 0.716 in equation 2 comes from the extraction frequency calibration and shows the relative drop in sensitivity going from an extraction frequency of $24 \mathrm{kHz}$ (used in lab) to $17 \mathrm{kHz}$ (used at SOAS). The value of 0.444 in equation 2 comes from the voltage settings calibration and shows the relative increase in sensitivity when operating under "clustered" voltage settings compared to "deculstered" settings.

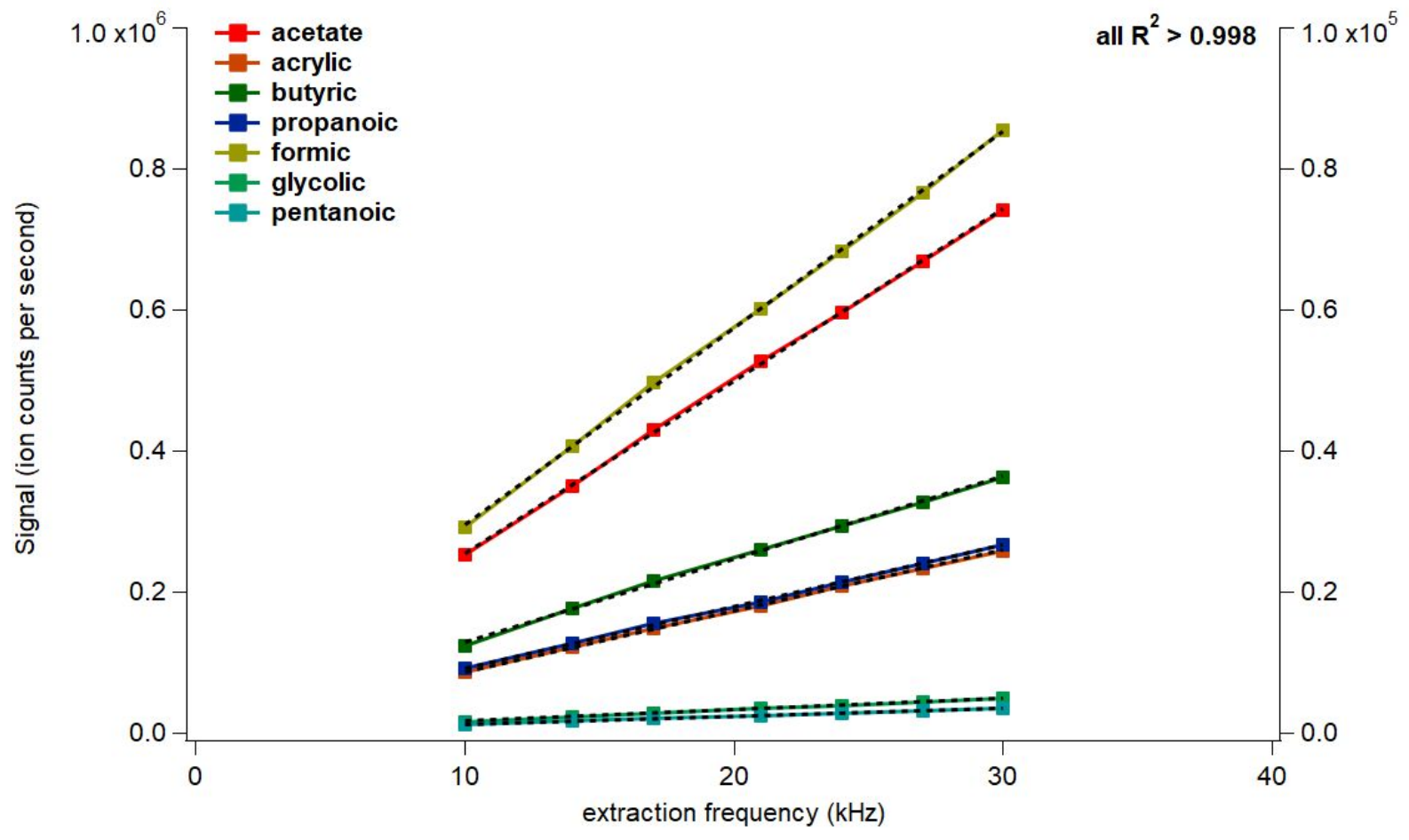


Figure S9. Signal as a function of ToF extraction frequency for select acids. Error bars representing the variability in the signal for each species during the measurement period are shown, but too small to be visible outside the markers.

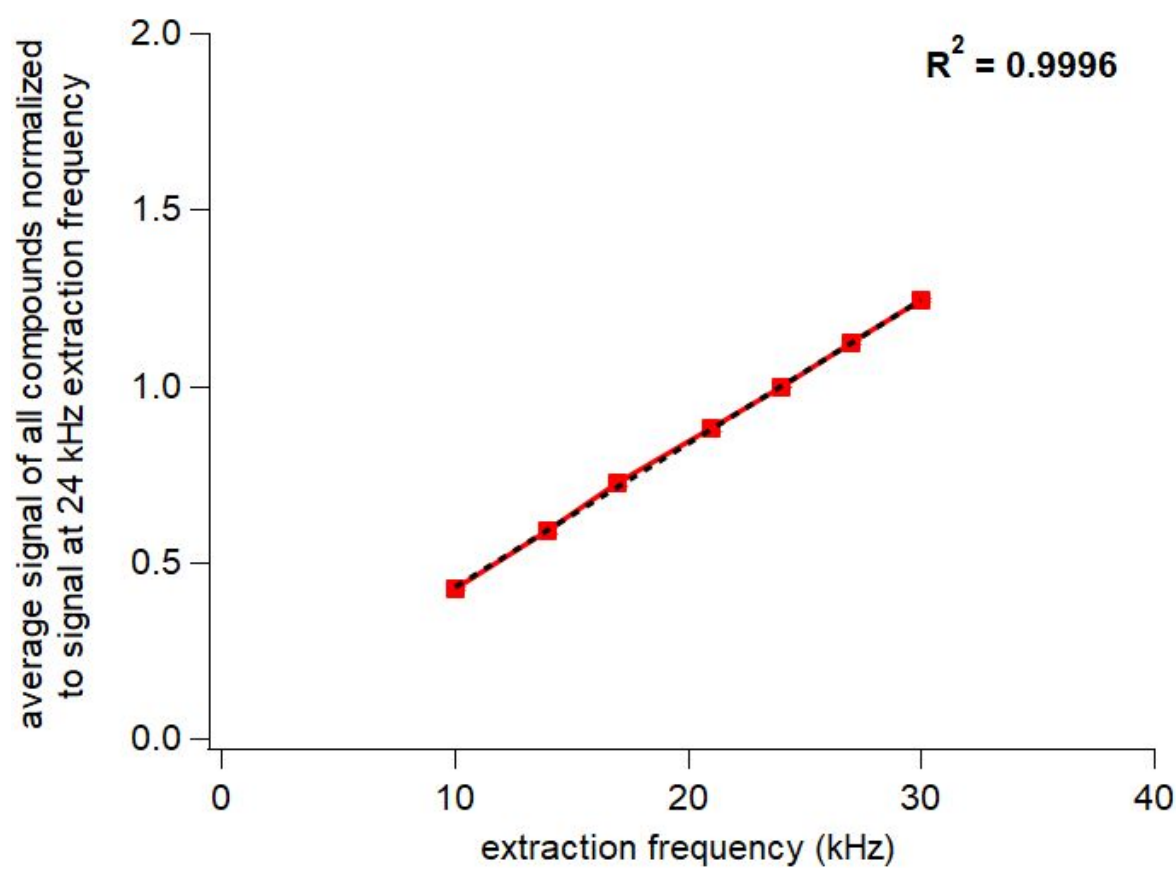

182 Figure S10. Average of all the signals in Figure S9 normalized to their signal at $24 \mathrm{kHz}$ and plotted as a function of ToF extraction frequency. Error bars representing the variability in the signal for each species during the measurement period are shown, but too small to be visible outside the markers.

185 Evidence that the method employed here to adjust sensitivities measured in lab to what the sensitivities would be when measured during the field campaigns is shown in the example of formic acid (Figure S11). Hourly calibrations of formic acid were performed during SOAS resulting in a campaign averaged sensitivity of $13 \pm 5 \mathrm{~Hz} \mathrm{ppt}_{\mathrm{v}}{ }^{-1}$ (Brophy and Farmer, 2015). Under the conditions that the instrument was operated in the lab a sensitivity to formic acid of $6.9 \pm 1 \mathrm{~Hz} \mathrm{ppt}_{\mathrm{v}}{ }^{-1}$ was measured. When this sensitivity was corrected for voltage settings (as determined by the average $\left[\mathrm{C}_{2} \mathrm{H}_{3} \mathrm{O}_{2}^{-}+\mathrm{C}_{2} \mathrm{H}_{4} \mathrm{O}_{2}\right] /\left[\mathrm{C}_{2} \mathrm{H}_{3} \mathrm{O}_{2}^{-}\right]$ratio measured during SOAS) and extraction frequency the "corrected" formic acid sensitivity expected at SOAS was calculated to be $10.9 \pm 3 \mathrm{~Hz} \mathrm{ppt}_{\mathrm{v}}{ }^{-1}$ falling well within error for the formic acid sensitivity measured at SOAS. 


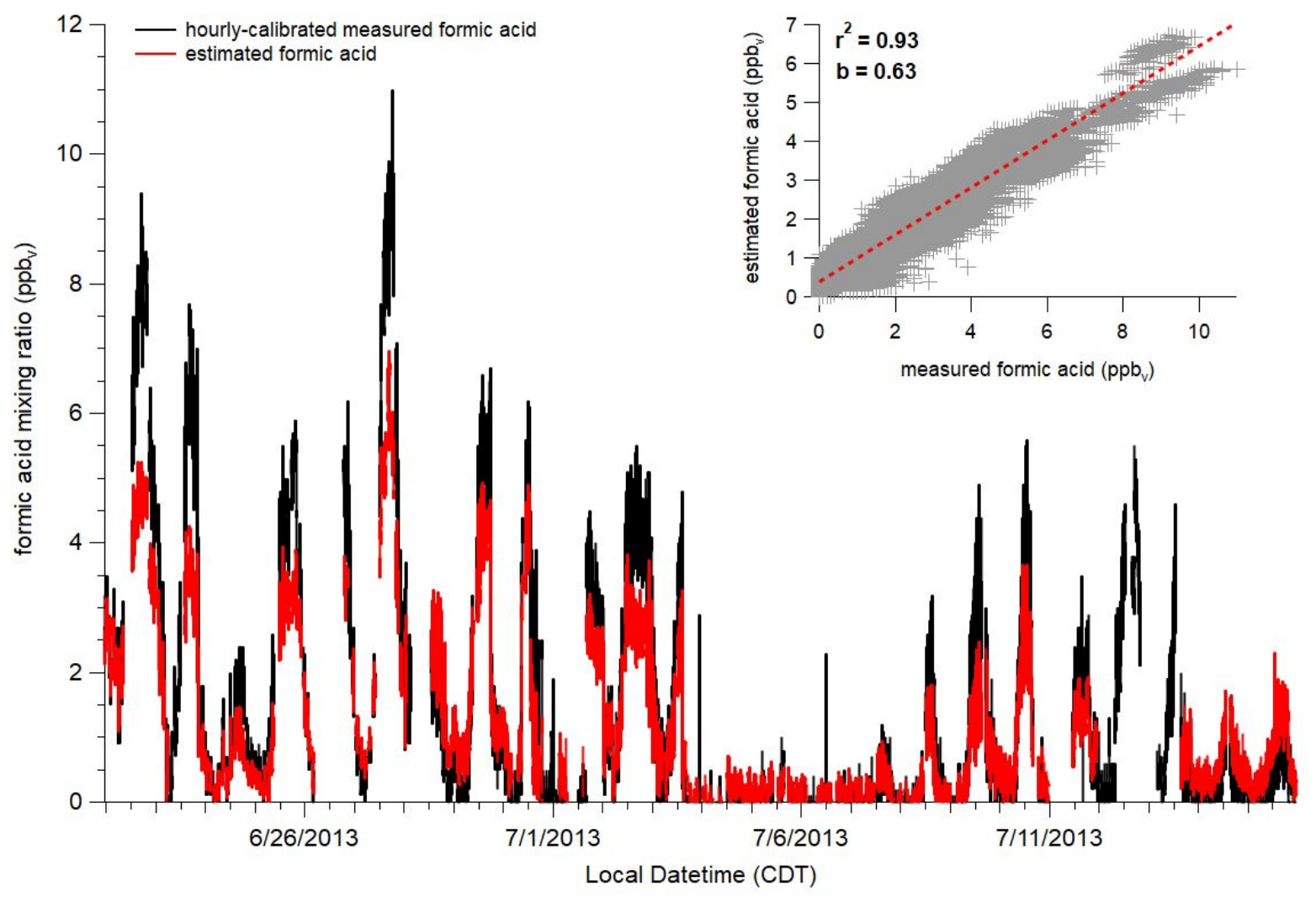

Figure S11. Comparison of formic acid mixing ratios calculated with sensitivities derived from using on-line hourly calibrations (black trace) versus estimation from the sensitivity parameterization (red trace).

A factor influencing the sensitivity of the CIMS during the SPiFFY campaign was the flowrate into the instrument. A larger orifice for the entrance of the IMR region was used during SPiFFY to maintain IMR pressure in-line with the low-pressure inlet. Calibrations were performed in lab to look at the relative change in sensitivity for select organic acids using the standard orifice inlet provided with delivery of the instrument, that produces a flowrate into the instrument of $2 \mathrm{sLpm}$, versus using the larger orifice.

An equation to convert sensitivities measured in lab to sensitivities that would have been measured during SPiFFY was derived as:

$$
\text { SPiFFY sensitivities }=\text { Lab sensitivities } \times 0.9 \times 1.86
$$

(equation 3)

The value of 0.9 in equation 3 comes from Figure S15 showing the relative drop in sensitivity going from an extraction frequency of $24 \mathrm{kHz}$ (used in lab) to $22 \mathrm{kHz}$ (used during SPiFFY). The value of 1.86 is the relative change in sensitivity when using the inlet with the larger orifice versus the standard orifice.

Quantification of all measured organic acids in mass spectrum. A multiple linear regression between the properties of average carbon oxidation state (OSc; OSc $\approx 2 \times \mathrm{O} / \mathrm{C}-\mathrm{H} / \mathrm{C}$ ), number of carbons (nC) and sensitivity for 12 different organic acid calibrants was used to parameterize sensitivity for all the organic acids measured by the acetate CIMS during SOAS/FIX-CIT and SPiFFY. Two separate multiple linear regressions were performed; one using the corrected sensitivities for SOAS/FIXCIT as inputs to the regression and the other using the corrected sensitivities for SPiFFY as inputs to the regression. The parameterizations for sensitivity for measured organic acids from the two campaigns are listed below in equations 4 and 5 . 
SOAS/FIXCIT campaign:

$$
\left.\log _{10}(\text { sensitivity })=(0.205 \times O S c)+(0.135 \times n C)+0.495 \text { (equation } 4\right)
$$

SPiFFY campaign:

$$
\left.\log _{10}(\text { sensitivity })=(0.205 \times \text { OSc })+(0.135 \times n C)+0.511 \text { (equation } 5\right)
$$

Bulk analysis of mass spectrum. Omission of species from bulk analysis were decided based on 2007; Wang et al., 2016). Because the primary mechanism for ionization in acetate CIMS is proton transfer from the analyte to the reagent (Brophy and Farmer, 2015; Veres et al., 2008) elemental formulae from the high-resolution peak list were analyzed by adding a hydrogen atom to the formula (i.e. formic acid is observed as $\mathrm{CHO}_{2}{ }^{-}$in the mass spectrum; here we modified the formula in the peak list to show $\mathrm{CH}_{2} \mathrm{O}_{2}$ ). All quantifiable species were assumed to contain a carboxylic acid moiety and so elemental formulae containing less than two oxygen atoms were excluded from bulk analysis. If the DBE was calculated to be a positive non-integer value, then the species was excluded from bulk analysis. Additionally, the elemental composition was constrained to $\mathrm{H} / \mathrm{C}$ and $\mathrm{O} / \mathrm{C}$ ratios of 0.3-3 and 0-3 (Wang et al., 2016). In the data processing procedures elemental formulae that violated these rules were flagged. Tentative explanations for flagged species are that these detected compounds are either clusters or fragments of molecules formed from unstable transmission through the instrument or reactions in the IMR (Brophy and Farmer, 2016). Table S4 presents many of the artifacts of the acetate CIMS measurement technique observed in the studies covered here. Despite all this knowledge and analysis, it is likely that some species identified in the mass spectrum as deprotonated neutral molecules are potentially clusters with the acetate reagent ion and thus measurement artifacts. However, if a species was identified as a cluster during the construction of the peak list that species was omitted from the bulk analysis. Elemental formulae in the peak list were also categorized into groups of organic acids with different functional groups per the method described in a previous publication (Liu et al., 2017). Briefly, the calculated degrees of unsaturation and the number of oxygens in the elemental formula were used as criteria to classify an elemental formula into an organic acid group (i.e., monosaturated acids, diacids/hydroxycarbonyl acids, hydroxyacids, etc.) If the formula did not satisfy the criteria placing it into a specific organic acid group that formula was classified as "ungrouped" and was not included in the bulk analysis.

SOAS bulk analysis details. An initial peak list was manually (i.e., no use of automated peak fitting procedures) constructed consisting of 660 high-resolution identified ions spanning $\mathrm{m} / \mathrm{z}$ 32-463. Very low signal above this (i.e., $\mathrm{m} / \mathrm{z} 463$ ) unit mass suggested that peaks above $\mathrm{m} / \mathrm{z} 463$ would make negligible contributions to the bulk analysis. In fact, integrated unit masses between $\mathrm{m} / \mathrm{z}$ 463-1047 contributed less than $1 \%$ to the total UMR signal (omitting the reagent $\mathrm{m} / \mathrm{z} 59$ ) for the entire campaign. From the initial list of 660 ions 416 contained only $\mathrm{C}, \mathrm{H}$ and $\mathrm{O}$. A total of 120 out of this set of 416 formulae were flagged for removal from the bulk analysis calculations. A total of 42 formulae were omitted from bulk analysis because they were identified as clusters. A total of $173 \mathrm{HR}$ assignments were classified as ungrouped and were not included in the bulk analysis. Some compounds met multiple exclusion criteria. After these exclusion criteria were applied to the peak list a total of 100 out 416 compounds containing C, $\mathrm{H}$ and $\mathrm{O}$ were used in the bulk analysis.

SPiFFY bulk analysis details. An initial peak list was manually constructed consisting of 583 highresolution identified ions spanning $\mathrm{m} / \mathrm{z}$ 32-304. Very low signal above this unit mass suggested that peaks above $\mathrm{m} / \mathrm{z} 304$ would make negligible contributions to the bulk analysis. From the initial list of 583 ions 337 contained only $\mathrm{C}, \mathrm{H}$ and $\mathrm{O}$. A total of 91 out of this set of 337 formulae were flagged for removal 
from the bulk analysis calculations. Because the declustering voltage settings were optimally tuned during this campaign no HR assignments were identified as clusters. A total of $146 \mathrm{HR}$ assignments were classified as ungrouped and were not included in the bulk analysis. Some compounds met multiple exclusion criteria. After these exclusion criteria were applied to the peak list a total of 100 out 337 compounds containing $\mathrm{C}, \mathrm{H}$ and $\mathrm{O}$ were used in the bulk analysis.

\section{Quantification of carbon and organic acid carbon yields from the FIXCIT experiments.} In Figure 3 in the main text the total carbon present in eight of the FIXCIT oxidation experiments is quantified and categorized. The three reservoirs for reacted carbon in the experiments are organic acid carbon, secondary organic aerosol (SOA) carbon and un-speciated carbon from other oxidation products (i.e. aldehydes, ketones, alcohols, ect.) not measured by the acetate CIMS. The total carbon in each experiment is determined by the carbon-equivalent mixing ratio of the parent VOC consumed during the experiment. For instance, the carbon-equivalent mixing ratio of $100 \mathrm{ppb}_{\mathrm{v}}$ of isoprene is $500 \mathrm{ppbC}$. The pie charts to the left of the bar plots in Figure 3 represent a snapshot of the distribution of carbon at some time near the end of each experiment. The parent VOC consumed is determined by subtracting the initial mixing ratio of VOC introduced into the chamber by the mixing ratio of VOC remaining at the time of the determination of the yield calculation. The mixing ratio of isoprene was determined by a co-located GCFID (Rivera-Rios et al., 2014) and the mixing ratio of a-pinene was determined from PTF-ToF measurements. The yield of SOA carbon was determined by dividing the concentration of OA, measured by a co-located HR-AMS, by an OM:OC ratio of 1.8 for a-pinene SOA (Chhabra et al., 2010) and 1.95 for isoprene SOA (Nguyen et al., 2010) and converting the carbon-equivalent mass to a mixing ratio. Organic acid carbon yield was determined in the following way. High-resolution peak fits were assigned to peaks from a list of species identified from the SOAS campaign. The final signal for all HR species was determined at some point near the end of an experiment. All species were normalized by the reagent and only organic acid species were considered for quantification. Mixing ratios for all organic acids were calculated based off the sensitivity parameterization described here. A background chamber measurement was made for the "low NO" and "high NO" + $\mathrm{OH}$ oxidation experiments. HR signals from these background chambers experiments were converted to mixing ratios, averaged, and subtracted from the VOC oxidation experiment mixing ratios to get background subtracted experiment mixing ratios. Carbon equivalent mixing ratios were determined by multiplying the HR species mixing ratio by the number of moles of carbon in the elemental formula. HR species were then lumped into C1, C2, C3, etc. grouped carbon-equivalent mixing ratios. Acetic acid, as measured by the Caltech ToF-CIMS was converted to a carbon-equivalent mixing ratio and added to the $\mathrm{C} 2$ group of organic acids. Acetic acid was background subtracted using the mixing ratios observed during the chamber blank experiments. Organic acid yields were calculated from the isoprene oxidation experiments by only including mixing ratios of organic acids with five carbons or less and yields were calculated from the a-pinene experiments using species with ten carbons or less. 


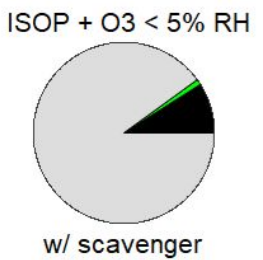

ISOP + O3 50\% RH

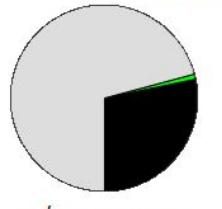

w/ scavenger

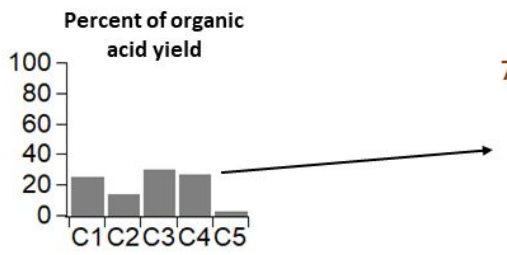

Organic acid carbon number

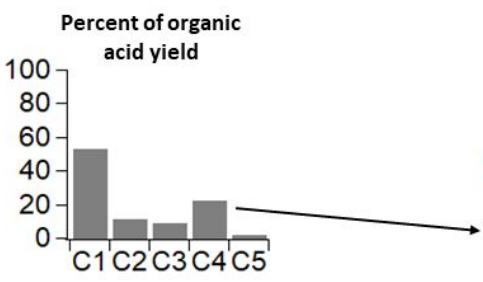

Organic acid carbon number

\section{Carbon-equivalent vields}

Gas-phase organic acids

Organic aerosol

Unspeciated oxidation products

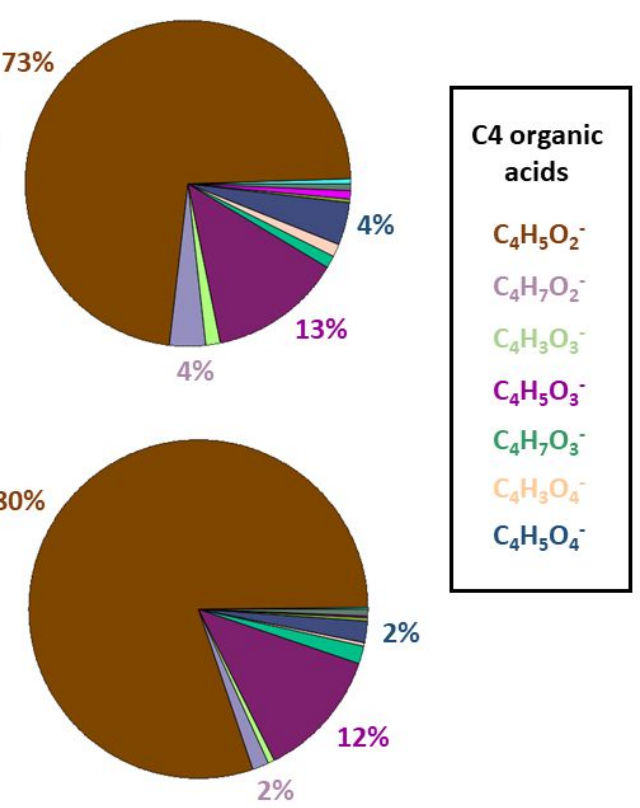

Figure S12. The pie charts on the right are taken from Figure 3 in the main text showing the contribution of organic acid carbon (black slice) to the total amount of isoprene carbon consumed in the "isoprene $+\mathrm{O}_{3}<5 \% \mathrm{RH}$ (with cyclohexane scavenger)" experiment (top) compared to the "isoprene $+\mathrm{O}_{3} 50 \% \mathrm{RH}$ (with cyclohexane scavenger)" experiment (bottom). The bar charts to the right of the pie charts show the carbon-equivalent yields of organic acids, organized by carbon number. The pie charts to the right of the bar charts showing the fractional contribution of $\mathrm{C} 4$ organic acids to the measured carbon-equivalent yields associated with $\mathrm{C} 4$ acids from the ozonolysis experiments. carbon-equivlent net production. 

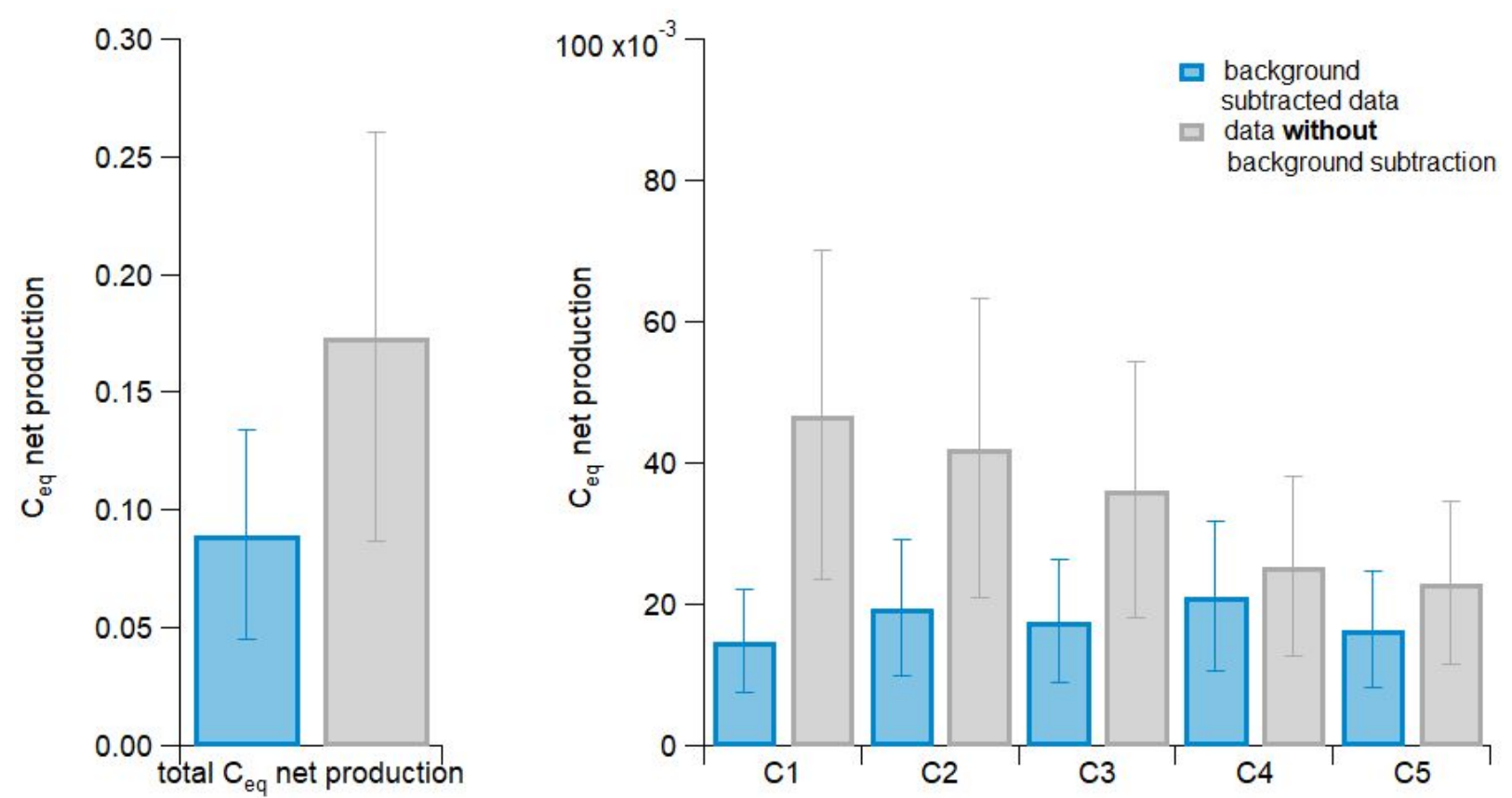

306

Figure S13. Comparison of organic acid carbon-equivalent net production values with (gray) and without (blue) background subtraction from the isoprene $+\mathrm{OH}$ "low NO" experiment. The left panel shows the effect of background subtraction on the total organic acid carbon quantified from the experiment and the right panel shows the same effect for organic acids differentiated by carbon number. Error bars show an estimated $\pm 50 \%$ uncertainty from organic acid quantification (see Figure 1 in main text).

Estimation of $\mathrm{O}_{3}$ oxidation contribution to "isoprene $+\mathrm{NO}_{3}$ " experiment yields. Approximately 40 $\mathrm{ppb}_{\mathrm{v}}$ of $\mathrm{O}_{3}$ was present in the "isoprene $+\mathrm{NO}_{3}$ " experiment to promote the formation of $\mathrm{NO}_{3}$ radicals. The observed organic acids produced were likely a result of combined $\mathrm{NO}_{3}$ and $\mathrm{O}_{3}$ oxidation chemistry. To place an upper bound on the contribution of $\mathrm{O}_{3}$ to the observed organic acid distribution we subtract the carbon-equivalent yields, as a function of carbon number, determined from the "isoprene $+\mathrm{OH}<5 \% \mathrm{RH}$ " (including the cyclohexane scavenger) experiment from the yields observed in the "isoprene $+\mathrm{NO}_{3}$ " experiment. We note the ozonolysis experiment has higher yields than the $\mathrm{NO}_{3}$ oxidation experiment of $\mathrm{C} 3$ and $\mathrm{C} 4$ acids suggesting this is in fact putting a lower bound on contribution of $\mathrm{NO}_{3}$ oxidation to organic acids. After accounting for potential $\mathrm{O}_{3}$ chemistry the total carbon-equivalent organic acid yield from the $\mathrm{NO}_{3}$ oxidation experiment was reduced from $\sim 16 \%$ to $\sim 11 \%$. Box-modeling of the "isoprene + $\mathrm{NO}_{3}$ " experiment showed that $77 \%$ of isoprene was lost to $\mathrm{NO}_{3}$ oxidation while $22 \%$ and $1 \%$ were lost to $\mathrm{O}_{3}$ and $\mathrm{OH}$ oxidation, respectively.

6. Treatment of CIMS data for PMF. Unit mass resolution (UMR) data were produced from Tofware v5.12 (via PMF analysis tools), calibration periods were removed, data were normalized to the reagent and background subtracted. For SOAS, time periods of precipitation or significant cloud cover were removed. Only $\mathrm{m} / \mathrm{z}$ from 38 to 400 were included in the analysis. These UMR matrices were then averaged to a 5-minute time base. Some UMR peaks were removed to help PMF analyze only UMRs not affected by some known form of interference. Some UMR peaks (such as $\mathrm{m} / \mathrm{z} 45$ for formic acid) were removed to aid in interpretability of PMF factors.

UMRs removed for the SOAS PMF analysis: $\mathrm{m} / \mathrm{z} 32\left(\mathrm{O}_{2}^{-}\right), 35\left(\mathrm{Cl}^{-}\right), 37\left({ }^{37} \mathrm{Cl}^{-}\right), 42\left(\mathrm{CNO}^{-}\right), 45\left(\mathrm{CHO}_{2}^{-}\right)$, $46\left(\mathrm{NO}_{2}^{-}\right), 59\left(\mathrm{C}_{2} \mathrm{H}_{3} \mathrm{O}_{2}^{-}\right.$; reagent), $60\left(\mathrm{CO}_{3}^{-}\right), 61,62\left(\mathrm{NO}_{3}^{-}\right), 69\left(\mathrm{CF}_{3}^{-}\right), 77$ (water cluster), $78\left(\mathrm{CO}_{3}\right.$ water cluster), $89\left(\mathrm{C}_{3} \mathrm{H}_{5} \mathrm{O}_{3}^{-}\right.$; mostly lactic acid $), 90\left(\mathrm{C}_{2} \mathrm{H}_{2} \mathrm{O}_{4}^{-}\right), 91\left(\mathrm{O}_{2}\right.$ cluster $), 94,113$, and $114\left(\mathrm{C}_{2} \mathrm{~F}_{3} \mathrm{O}_{2}{ }^{-}\right.$; 
tubing), 119 (reagent cluster), 166 (reagent autoxidation product cluster), 179 (acetic acid double cluster); $163,169,213,219,263,269,313$, and 319 (tubing artifacts).

UMRs removed for the SPiFFY analysis: $32\left(\mathrm{O}_{2}^{-}\right), 35\left(\mathrm{Cl}^{-}\right), 37\left({ }^{37} \mathrm{Cl}^{-}\right), 42\left(\mathrm{CNO}^{-}\right), 45\left(\mathrm{CHO}_{2}^{-}\right), 46\left(\mathrm{NO}_{2}^{-}\right)$, $59\left(\mathrm{C}_{2} \mathrm{H}_{3} \mathrm{O}_{2}-\right.$; reagent $), 60\left(\mathrm{CO}_{3}^{-}\right), 61,62\left(\mathrm{NO}_{3}^{-}\right), 69\left(\mathrm{CF}_{3}^{-}\right), 113$, and $114\left(\mathrm{C}_{2} \mathrm{~F}_{3} \mathrm{O}_{2}^{-}\right.$; tubing); 163, 169, 213, $219,263,269,313$, and 319 (tubing artifacts).

\section{Comparison of formic acid carbon-equivalent yields measured by different chemical} ionization methods. We use measurements of acetic acid from a co-located $\mathrm{CF}_{3} \mathrm{O}^{-} \mathrm{CIMS}$ during FIXCIT to help quantify the contribution of organic acids to total carbon yields from isoprene and $\alpha$ pinene oxidation. We use acetic acid measurements from the $\mathrm{CF}_{3} \mathrm{O}^{-} \mathrm{CIMS}$ also to quantify total carbonequivalent mixing ratios observed during SOAS. Iodide CIMS $\left(\mathrm{I}^{-}\right)$measurements were used to help identify clusters observed from acetate CIMS measurements during SOAS and FIXCIT. To validate comparisons and cross-application of measurements across ionization techniques we compared formic acid carbon-equivalent yields calculated from the FIXCIT experiments by $\mathrm{CF}_{3} \mathrm{O}^{-}$, $\mathrm{I}^{-}$, and acetate CIMS. Absolute values of yields agree well compared to one another, but, more importantly, all the measured yields fall within error of one another except for the "high NO" experiments where organic acid yields overall were very low.

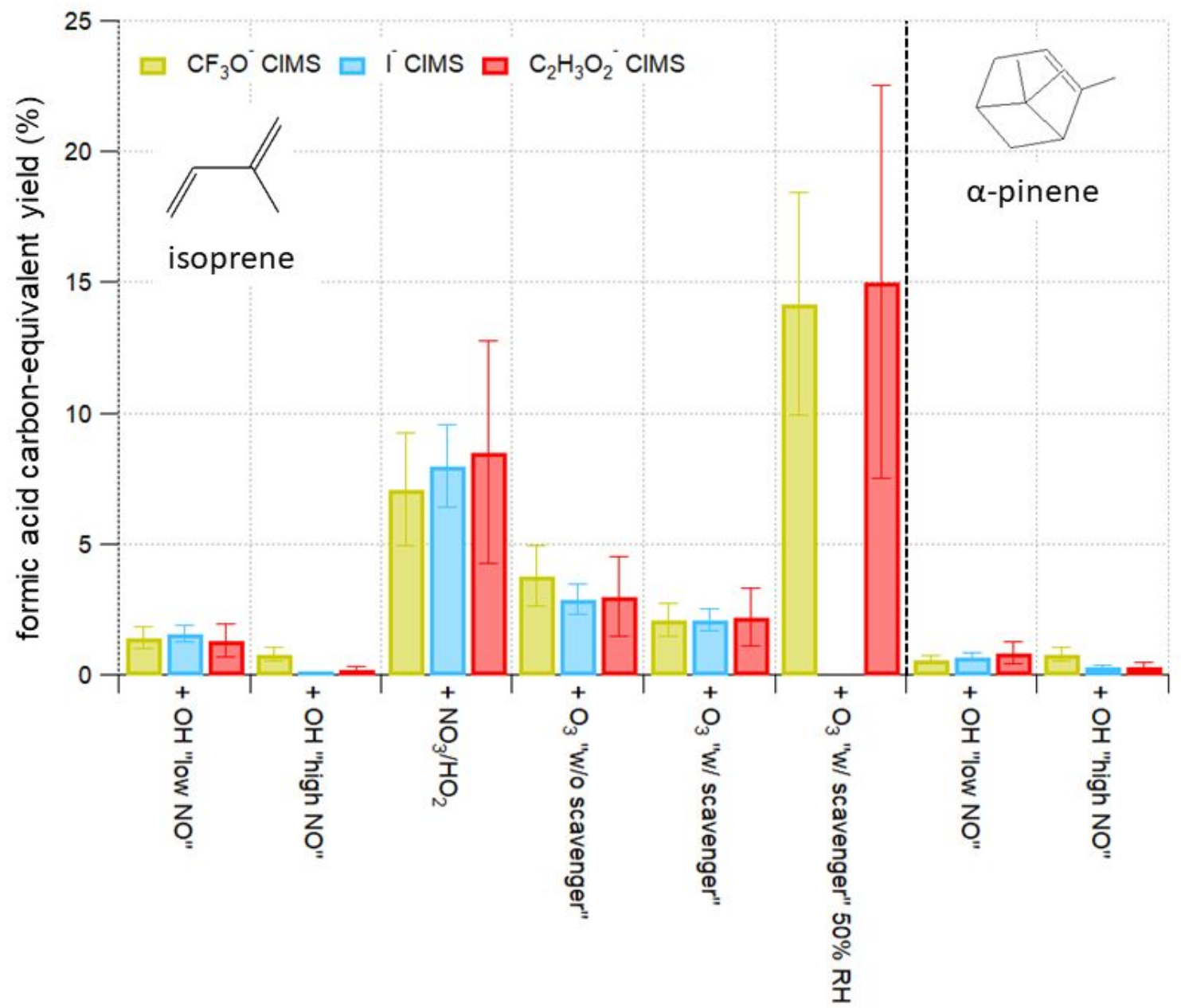


Figure S14. Formic acid carbon-equivalent yields from isoprene (left of dashed black line) and $\alpha$-pinene (right of dashed black line) experiments as determined by measurements from $\mathrm{CF}_{3} \mathrm{O}^{-}$(yellow), $\mathrm{I}^{-}$(blue), and acetate (red) CIMS. Error associated with $\mathrm{CF}_{3} \mathrm{O}^{-}, \mathrm{I}^{-}$, and acetate is 30,20 , and $50 \%$, respectively.
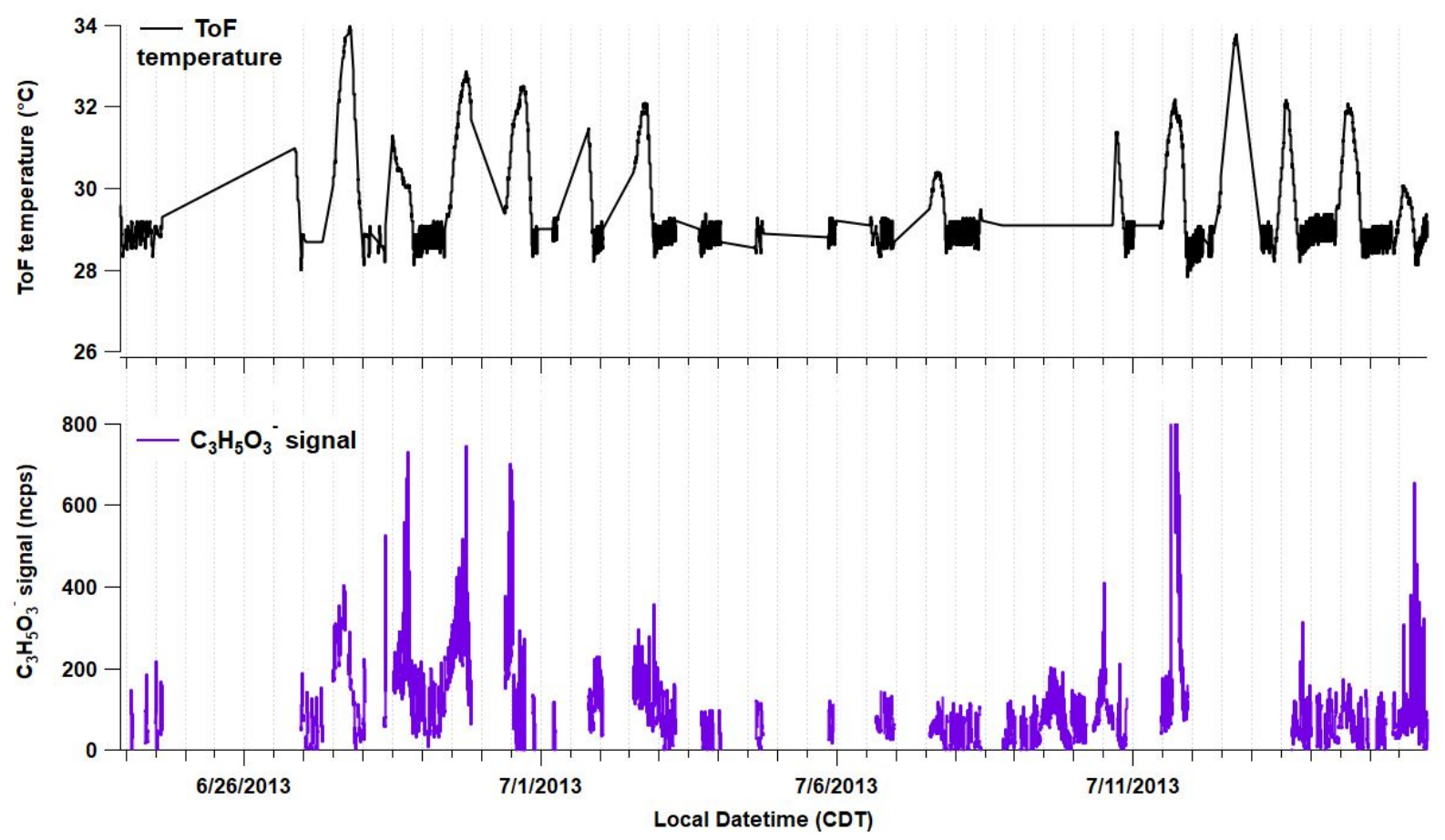

Figure S15. Time series of ToF temperature (top panel; black) and an example ion, $\mathrm{C}_{3} \mathrm{H}_{5} \mathrm{O}_{3}{ }^{-}$(bottom panel; purple). Fine oscillations in the ToF temperature, caused by changes in the temperature of the trailer where the acetate CIMS was located, created oscillations in the signal of many measured organic acids such as $\mathrm{C}_{3} \mathrm{H}_{5} \mathrm{O}_{3}$.
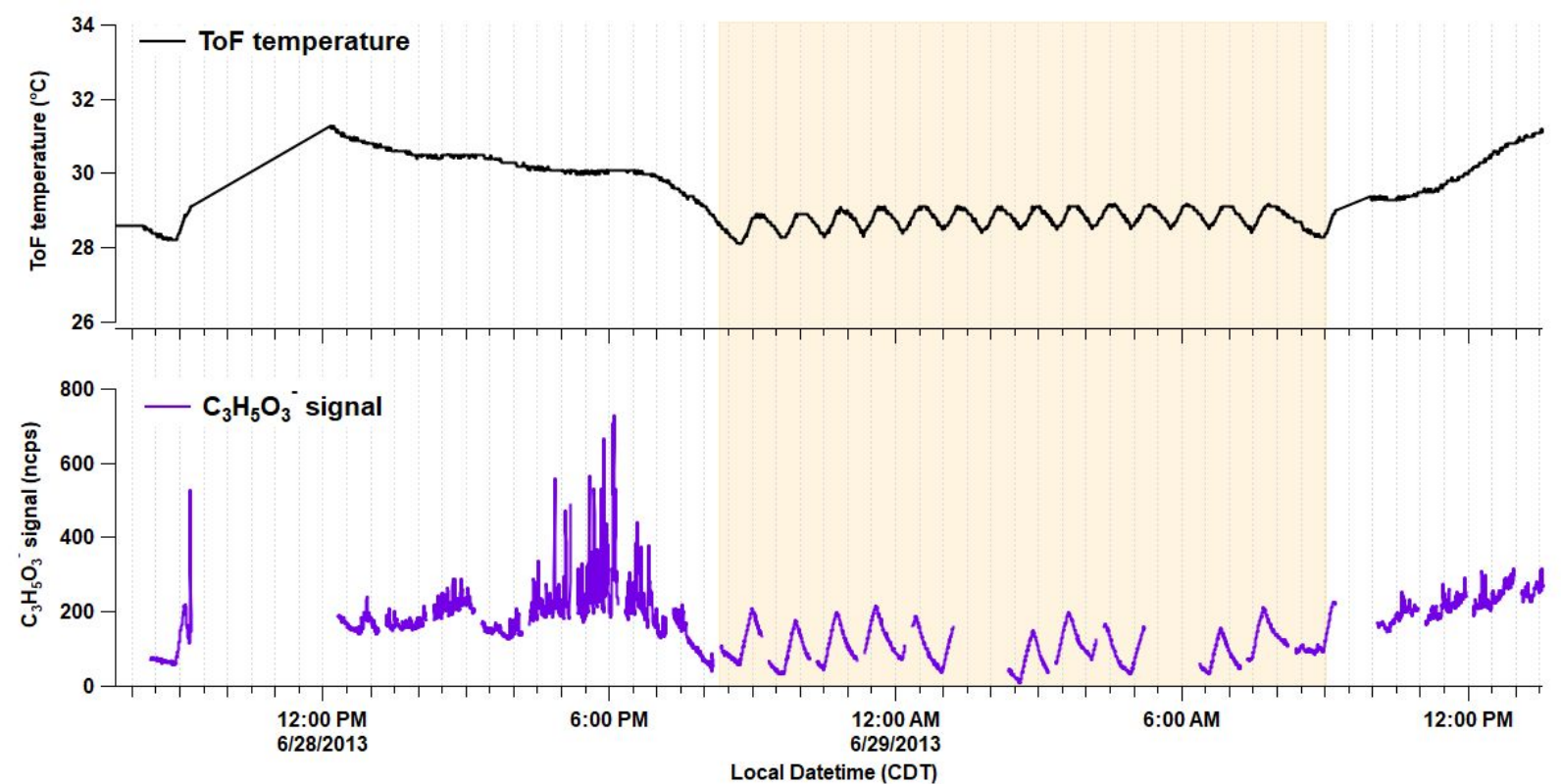
Figure S16. The time series in Figure S15 are zoomed in to a period on the $29^{\text {th }}$ to show greater detail in the structure of the interference. The shaded area indicates a time where the temperature-driven artifact was active.

9. Determination of PMF solutions for SOAS and SPIFFY. We performed two types of analyses to determine the stability of PMF factors and find evidence for factor-splitting; (1) PMF factor signal allocation analysis and (2) correlation of PMF factor diel profiles with high-resolution identified species diel profiles from the acetate CIMS.

To perform the first analysis, we took the campaign-integrated signal from the time series of each PMF factor and divided it by the total measured UMR signal to get a PMF factor fractional contribution to the total UMR signal for each PMF solution (Figures S17 and S18). This analysis shows how the total UMR signal is allocated to each factor as a function of PMF solution.

To perform the second analysis, we calculated diel profile campaign medians for both PMF factors and high-resolution identified species (659 unique species for SOAS and 579 for SPiFFY). We then determined which factors' diel profile a given high-resolution species' diel profile had the highest correlation with above a minimum correlation value $(\mathrm{r}=0.80)$. If the high-resolution species did not correlate with any PMF factor above the minimum value, it was categorized as correlated with "no factor". This analysis provided information on how much additional correlation with high-resolution species was obtained as a function of PMF solution.

UMR time series signal allocation to PMF factor analysis. Barplots showing the percent contribution of time series signal from PMF factors from each PMF solution are shown in Figures S17 (SOAS) and S18 (SPiFFY).

Going from a five to six factor solution a portion of the signal allocated to the isoprene $\mathrm{RO}_{2}+\mathrm{HO}_{2}$ factor gets allocated to the isoprene $\mathrm{RO}_{2}+\mathrm{NO}$ factor. This is a stable change because, going from the six to seven factor solution, the relative amount of signal allocated to the two isoprene factors is similar. Because the amount of signal that is allocated to the tubing and $\mathrm{A} / \mathrm{C}$ unit factors is relatively constant through all solutions these factors are stable. Going from the six to the seven-factor solution part of the signal from the $\mathrm{A} / \mathrm{C}$ unit factor and the isoprene $\mathrm{RO}_{2}+\mathrm{NO}$ factor is allocated to a new factor that is likely a split from these two factors. The diel profile of this new factor is most similar to the $\mathrm{A} / \mathrm{C}$ unit factor and decreases the overall interpretability of the six-factor solution. This analysis also shows that the biogenic factor comprises a significant portion of the total UMR signal and is stable across all the solutions shown here. 


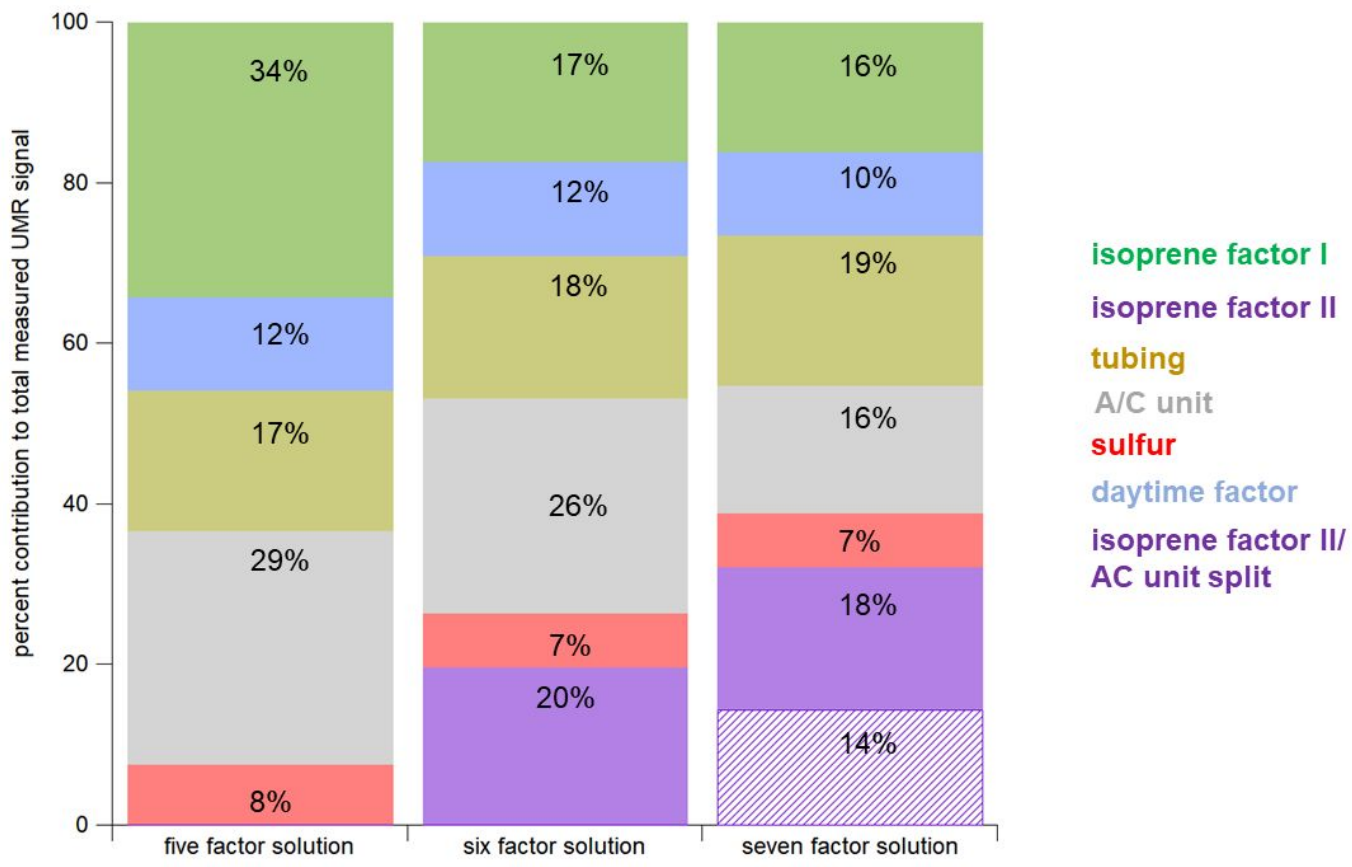

Figure S17. Percent contribution of each SOAS PMF factor signal—-from campaign-integrated time series signal from the five, six and seven factor solutions - to the total measured UMR signal. The boxes with the dashes indicate contributions from splits of factors in previous solutions.

394 Factor splitting is observed for the SPiFFY PMF solutions going from a five to a six-factor solution. The new factor that appears in the six-factor solution has diel characteristics taken from all the daytime factors and does not increase the interpretability of the PMF results. 


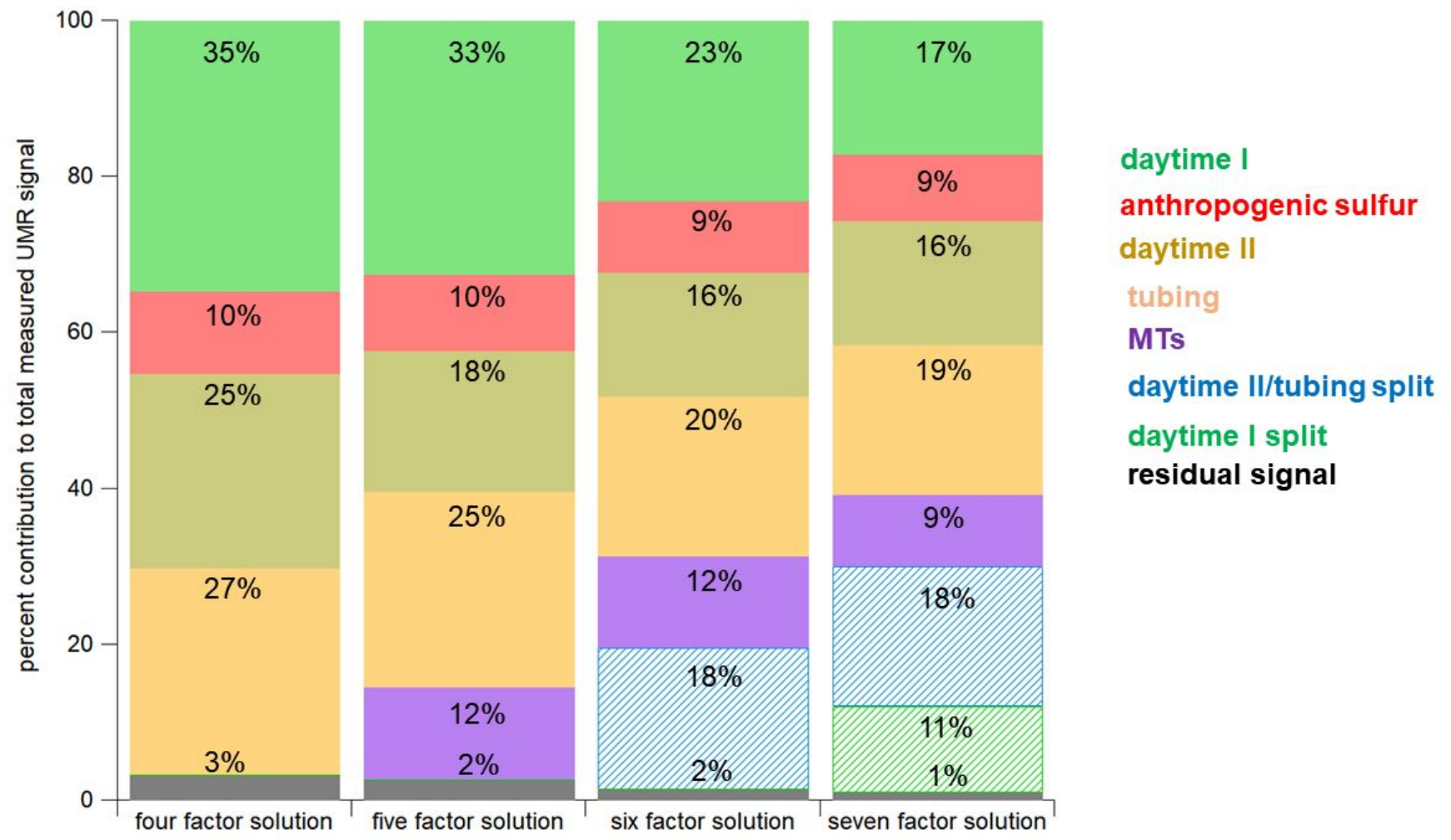

Figure S18. Percent contribution of each SPiFFY PMF factor signal—-from campaign-integrated time series signal from the four, five, six and seven factor solutions - to the total measured UMR signal. The boxes with the dashes indicate contributions from splits of factors in previous solutions.

High-resolution species diel profile correlation analysis with PMF factors. Pie charts showing the number of HR species whose diel profile correlated with PMF factor diel profiles (expressed as a percentage), above a value of $r=0.80$, are shown in Figures S19 (SOAS) and S20 (SPiFFY).

404 Though the two isoprene factors have similar signature of daytime photochemical production, the HR 405 analysis suggests going from a five to a six-factor solution increases the interpretability of the PMF factors. In the six-factor solution the "isoprene $\mathrm{RO}_{2}+\mathrm{NO}$ " factor is created from signal originally allocated to the "isoprene $\mathrm{RO}_{2}+\mathrm{HO}_{2}$ " factor. Because many of the $\mathrm{HR}$ species that originally correlated with the " $\mathrm{RO}_{2}+\mathrm{HO}_{2}$ " factor from the five factor solution correlate with the " $\mathrm{RO}_{2}+\mathrm{NO}$ " factor without an increase in the contribution to the number of species that are classified as "no factor" we determine that the six factor solution is stable. Increasing to a seven-factor solution does not increase the 411 interpretability of the PMF factors and results in splitting of the " $\mathrm{RO}_{2}+\mathrm{NO}$ " factor. 


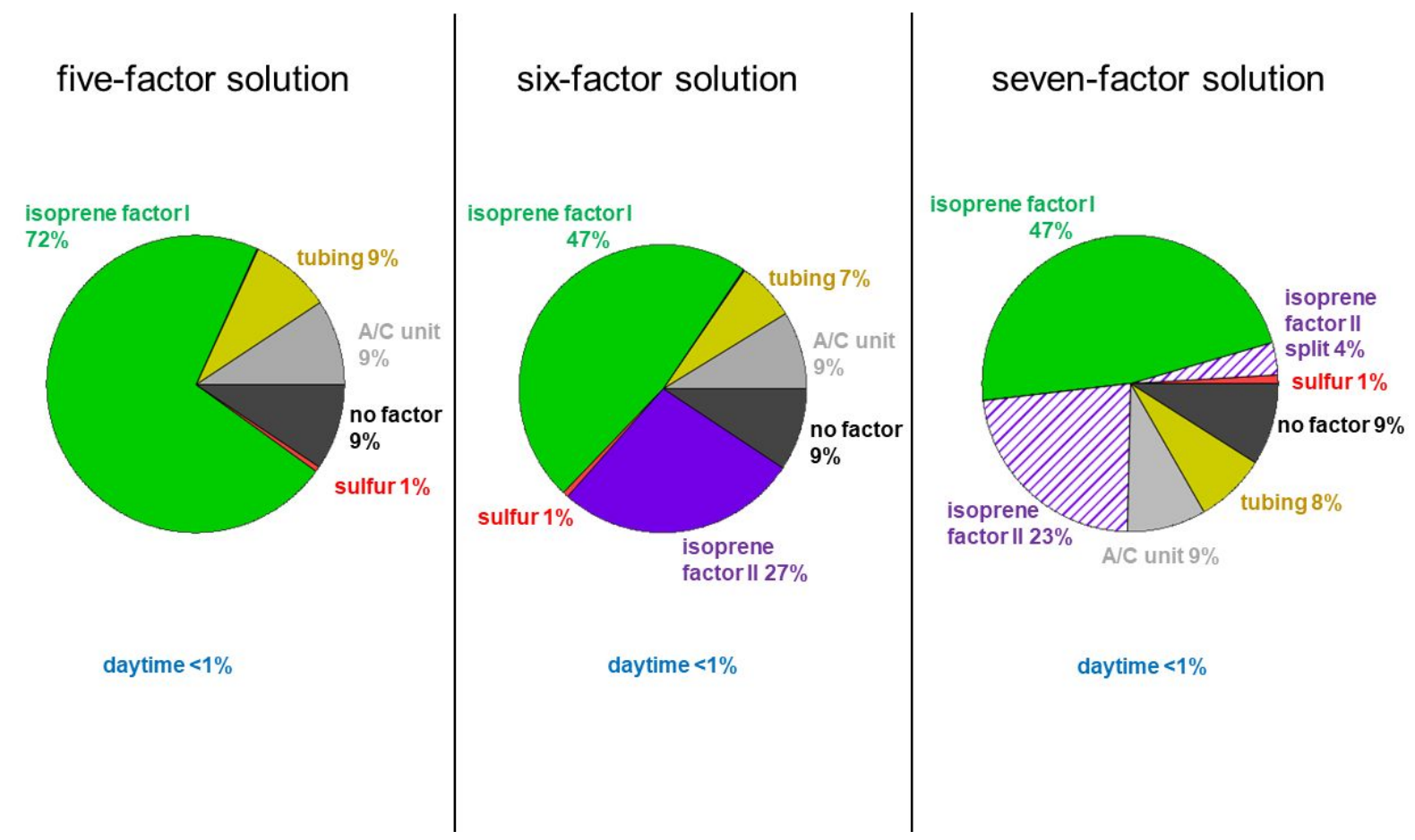

Figure S19. High-resolution comparison with UMR-based PMF factors corresponding to five to seven factor 414 solution for the SOAS campaign. The total number of HR species correlated to PMF factors for this analysis was 415 659. Dashed areas show factors that have split as solution factor number increases.

416 Going from a five to six factor solution, the additional factor that is added does not correlate well with 417 many HR species and does not add to the interpretability of the five-factor solution.

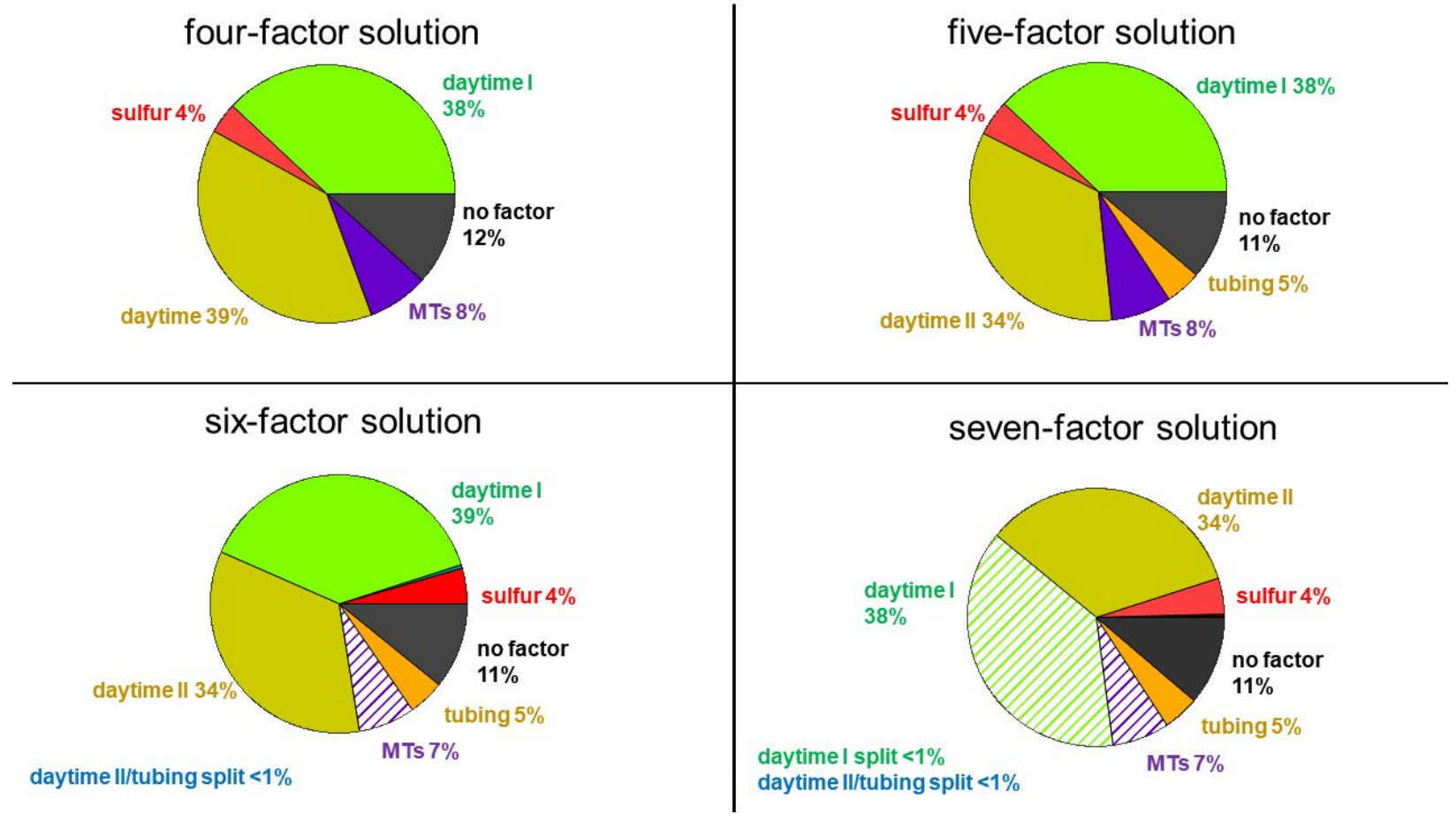


Figure S20. Same as Figure S19 shown for the four to seven factor solutions for SPiFFY. The total number of HR species correlated to PMF factors for this analysis was 579. Dashed areas show factors that have split as solution factor number increases.

10. Supplemental discussion of PMF factors. Below we show the full time series and mass spectra for the PMF solutions from both SOAS and SPiFFY.

\section{SOAS PMF six-factor solution.}
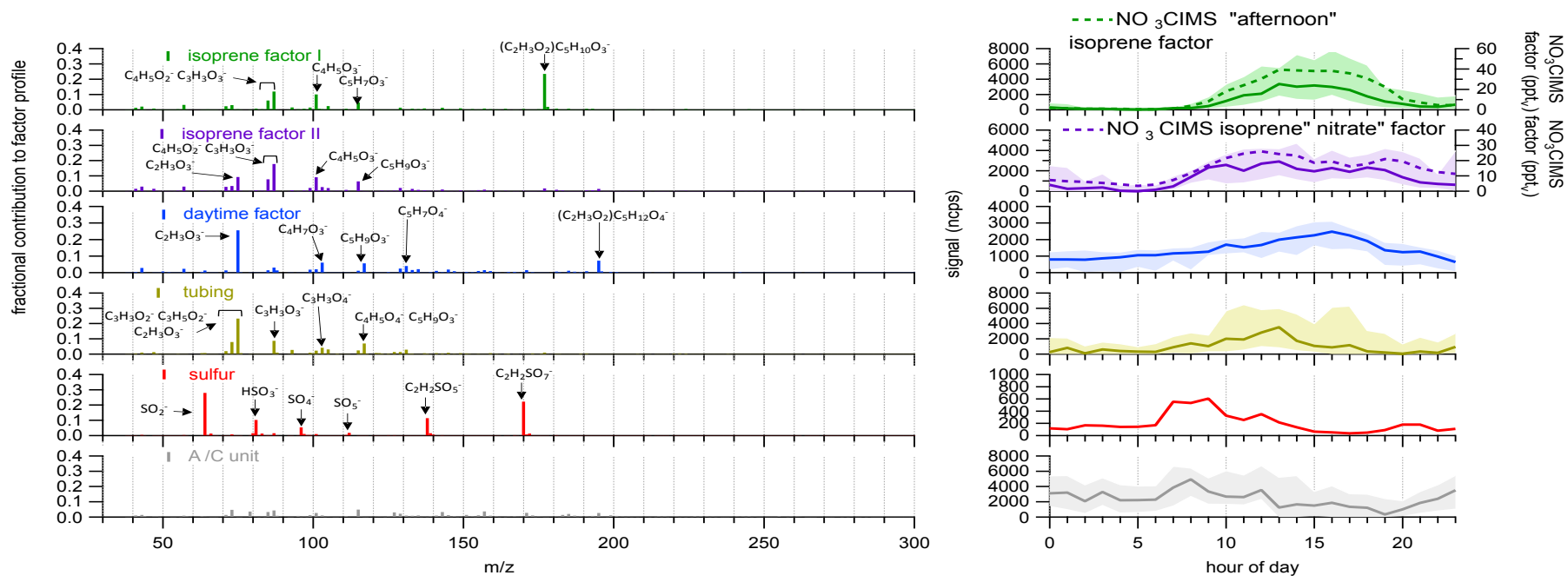

425

426

427

428

429

430

431

432

433

434

435

436

437

438

439

440

441

442

443

444

445

446

Figure S21. Mass spectra (left) and diel time series (right) for the six factors from the PMF solution for SOAS. The peaks in the factor mass spectra are presented as fractional contributions to the total composition of the factor (i.e., a peak with an intensity of 0.2 would represent $20 \%$ of the factor's signal). The factors include "isoprene factor I" (green, top), "daytime factor" (blue), "isoprene factor II" (purple), "tubing” (yellow), "sulfur" (red), and "A/C unit" (gray, bottom). Important species associated with the factors are identified with arrows in the mass spectra and described by the conjugate base of the organic acid analyte or as a reagent cluster. Diel profiles represent campaign medians, and the shaded areas show the interquartile range.

- A "tubing artifact" factor: Despite removing ions typically associated with measurement artifacts, our six-factor solution includes a factor we attribute to molecules emitted from inlet tubing. This factor correlates well with solar radiation and the $\mathrm{CF}_{3} \mathrm{O}^{-}$ion, a well-known artifact of PFA tubing. This factor includes $\mathrm{C}_{3} \mathrm{H}_{4} \mathrm{O}_{2}$ (acrylic acid), $\mathrm{C}_{3} \mathrm{H}_{4} \mathrm{O}_{3}$ (pyruvic acid), and $\mathrm{C}_{3} \mathrm{H}_{4} \mathrm{O}_{4}$ (malonic acid), suggesting that these species are either directly emitted by tubing, or are susceptible to partitioning to tubing walls and re-emission as the tubing warms.

- A "sulfur" factor: This factor includes $\mathrm{SO}_{2}{ }^{-}, \mathrm{SO}_{3}^{-}, \mathrm{SO}_{5}^{-}$, and two sulfur-containing organic ions in the mass spectrum. $\mathrm{SO}_{2}^{-}$signals in the acetate CIMS correlate well with observed $\mathrm{SO}_{2(\mathrm{~g})}\left(\mathrm{r}^{2}=\right.$ 0.86). The timeseries of this factor is irregular, consistent with regional transport of sulfur to the site from anthropogenic sources.

- An "A/C unit" factor: The air-conditioning (A/C) unit in the trailer cycles, creating an oscillating CIMS signal (Figures S15 and S16). This interference affected all ions in the mass spectrum, but most strongly impacted ions with low signal-to-noise ratios and compounds expected to have a high affinity for partitioning to surfaces (e.g., lactic acid, $\mathrm{C}_{3} \mathrm{H}_{5} \mathrm{O}_{3}$ ). Two processes may be 
contributing to the A/C factor: (i) wall-desorption processes on the tubing and instrument inlet, and (ii) physical changes in the instrument (e.g., expansion/contraction of ToF region).

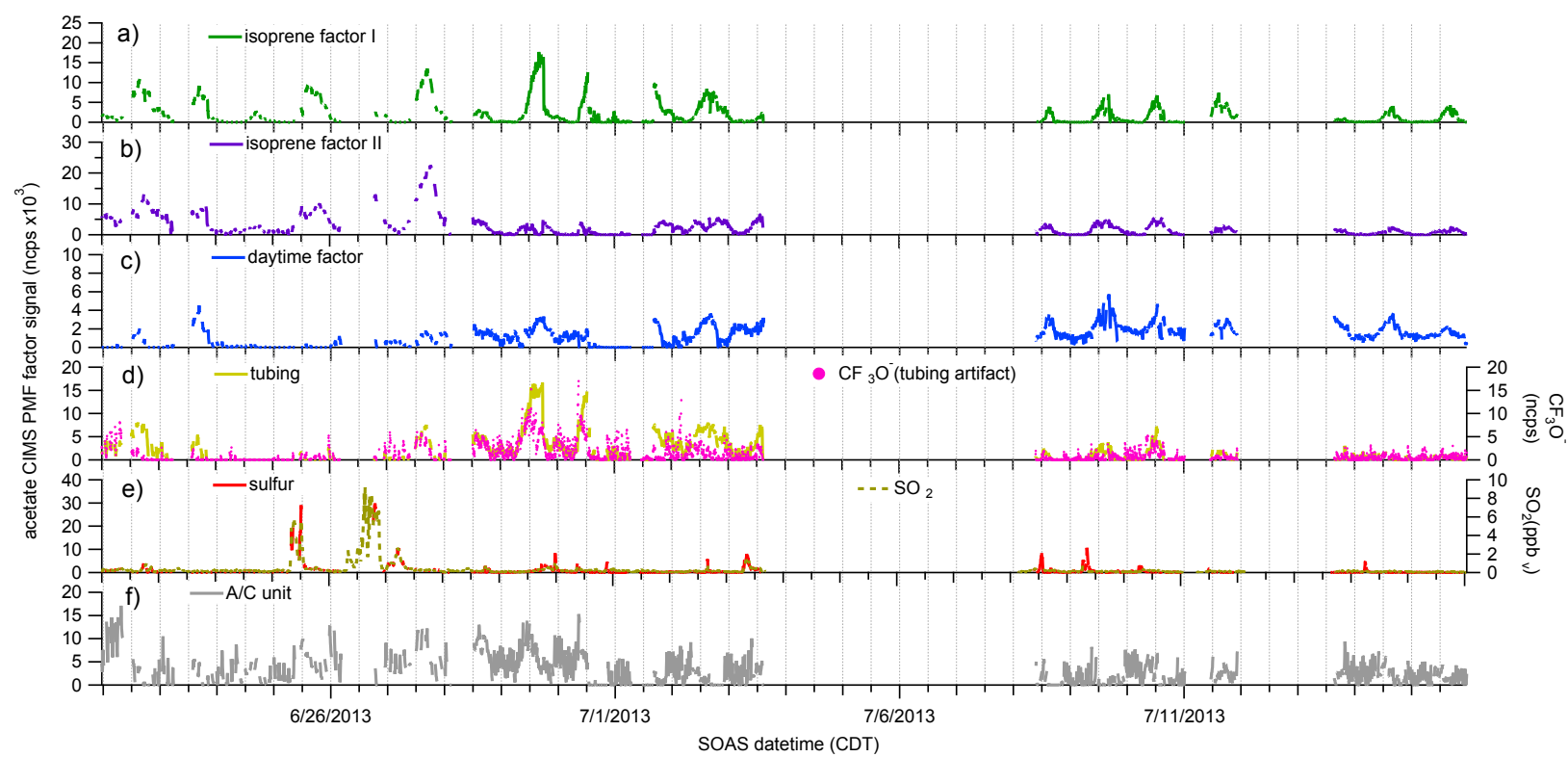

Figure S22. SOAS PMF factor time series.
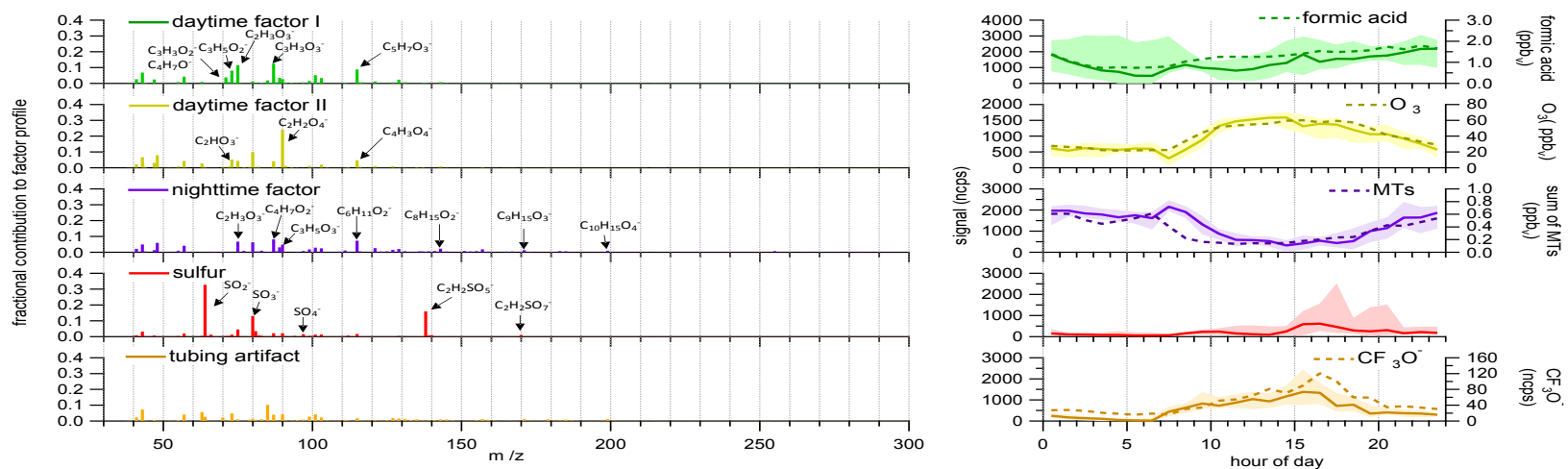

Figure S23. Mass spectra (left) and diel time series (right) for the five factors from the PMF solution for SPiFFY. 


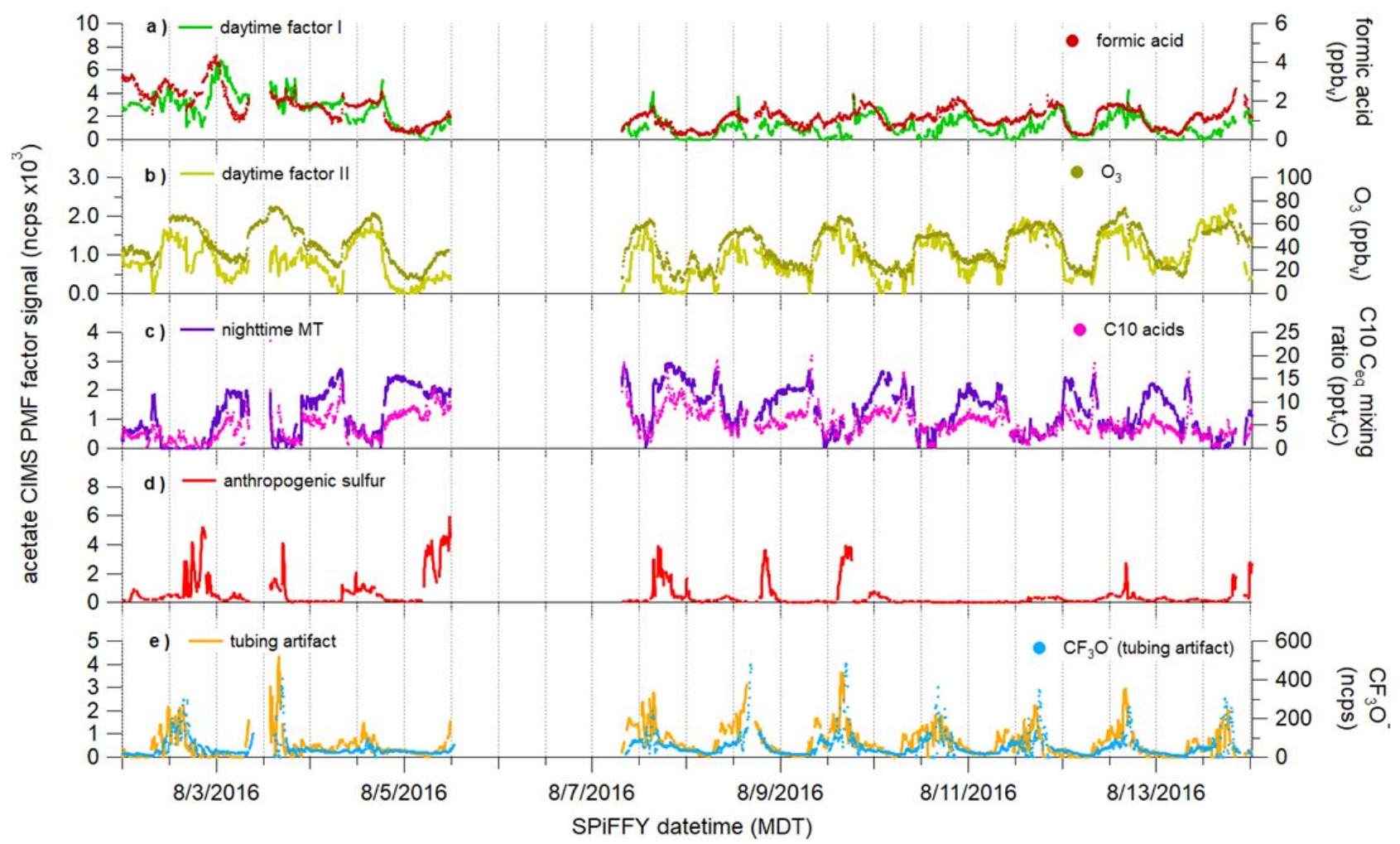

Figure S24. SPiFFY PMF factor time series. Species correlated with PMF factors-formic acid, C10 acids, and $\mathrm{CF}_{3} \mathrm{O}^{-}-$-were measured by the acetate $\mathrm{CIMS}$.

459

460

461

462

463

464

465

466

467

468

469

470

471

472

473

474

475

476

477
- "Anthropogenic sulfur": Similar to SOAS, we observe an "anthropogenic sulfur" factor associated with regional transport of pollutants. Transport of pollution from Denver and Colorado Springs has been previously reported to influence $\mathrm{RO}_{2}$ termination through increased reaction with $\mathrm{NO}$ over $\mathrm{HO}_{2}$ (Ortega et al., 2014). However, $\mathrm{SO}_{2}$ and its accompanying pollutants do not obviously affect the organic acid concentration or distribution.

- "Tubing artifact": Despite extensive filtering of the mass spectra, we identified a factor that correlated well with tracers of tubing emissions, including $\mathrm{CF}_{3} \mathrm{O}^{-}$and $\mathrm{C}_{2} \mathrm{~F}_{3} \mathrm{O}_{2}{ }^{-}$. Like SOAS, many acids correlate with this factor, indicating that they are susceptible to partitioning to the inlet tubing.

\section{References}

Brophy, P. and Farmer, D. K.: A switchable reagent ion high resolution time-of-flight chemical ionization mass spectrometer for real-time measurement of gas phase oxidized species: characterization from the 2013 southern oxidant and aerosol study, Atmos Meas Tech, 8(7), 2945-2959, https://doi.org/10.5194/amt-8-2945-2015, 2015.

Brophy, P. and Farmer, D. K.: Clustering, methodology, and mechanistic insights into acetate chemical ionization using high-resolution time-of-flight mass spectrometry, Atmos Meas Tech, 9(8), 3969-3986, https://doi.org/10.5194/amt-9-3969-2016, 2016.

Budisulistiorini, S. H., Li, X., Bairai, S. T., Renfro, J., Liu, Y., Liu, Y. J., McKinney, K. A., Martin, S. T., McNeill, V. F., Pye, H. O. T., Nenes, A., Neff, M. E., Stone, E. A., Mueller, S., 
Knote, C., Shaw, S. L., Zhang, Z., Gold, A. and Surratt, J. D.: Examining the effects of anthropogenic emissions on isoprene-derived secondary organic aerosol formation during the 2013 Southern Oxidant and Aerosol Study (SOAS) at the Look Rock, Tennessee ground site, Atmos Chem Phys, 15(15), 8871-8888, https://doi.org/10.5194/acp-15-8871-2015, 2015.

Chhabra, P. S., Flagan, R. C. and Seinfeld, J. H.: Elemental analysis of chamber organic aerosol using an aerodyne high-resolution aerosol mass spectrometer, Atmospheric Chem. Phys., 10(9), 4111-4131, https://doi.org/10.5194/acp-10-4111-2010, 2010.

Deming, B., Pagonis, D., Liu, X., Day, D., Talukdar, R., Krechmer, J., Gouw, J. A. de, Jimenez, J. L. and Ziemann, P. J.: Measurements of Delays of Gas-Phase Compounds in a Wide Variety of Tubing Materials due to Gas-Wall Interactions, Atmospheric Meas. Tech. Discuss., 1-19, https://doi.org/10.5194/amt-2019-25, 2019.

Inomata, S. and Hirokawa, J.: Non-radioactive Chemical Ionization Mass Spectrometry Using Acetic Acid-Acetate Cluster as a Reagent Ion for the Real-time Measurement of Acids and Hydroperoxides, Chem. Lett., 46(1), 38-41, https://doi.org/10.1246/cl.160828, 2016.

Kind, T. and Fiehn, O.: Seven Golden Rules for heuristic filtering of molecular formulas obtained by accurate mass spectrometry, BMC Bioinformatics, 8, 105, https://doi.org/10.1186/1471-2105-8-105, 2007.

Krechmer, J. E., Pagonis, D., Ziemann, P. J. and Jimenez, J. L. L.: Quantification of gas-wall partitioning in Teflon environmental chambers using rapid bursts of low-volatility oxidized species generated in-situ, Environ. Sci. Technol.

http://pubs.acs.org/doi/abs/10.1021/acs.est.6b00606, last access: 18 January 2017, 2016.

Lee, B. H., Lopez-Hilfiker, F. D., Veres, P. R., McDuffie, E. E., Fibiger, D. L., Sparks, T. L., Ebben, C. J., Green, J. R., Schroder, J. C., Campuzano-Jost, P., Iyer, S., D’Ambro, E. L., Schobesberger, S., Brown, S. S., Wooldridge, P. J., Cohen, R. C., Fiddler, M. N., Bililign, S., Jimenez, J. L., Kurtén, T., Weinheimer, A. J., Jaegle, L. and Thornton, J. A.: Flight Deployment of a High-Resolution Time-of-Flight Chemical Ionization Mass Spectrometer: Observations of Reactive Halogen and Nitrogen Oxide Species, J. Geophys. Res. Atmospheres, 123(14), 76707686, https://doi.org/10.1029/2017JD028082, 2018.

Liu, S., Thompson, S. L., Stark, H., Ziemann, P. J. and Jimenez, J. L.: Gas-Phase Carboxylic Acids in a University Classroom: Abundance, Variability, and Sources, Environ. Sci. Technol., 51(10), 5454-5463, https://doi.org/10.1021/acs.est.7b01358, 2017.

Lopez-Hilfiker, F. D., Mohr, C., Ehn, M., Rubach, F., Kleist, E., Wildt, J., Mentel, Th. F., Lutz, A., Hallquist, M., Worsnop, D. and Thornton, J. A.: A novel method for online analysis of gas and particle composition: description and evaluation of a Filter Inlet for Gases and AEROsols (FIGAERO), Atmos Meas Tech, 7(4), 983-1001, https://doi.org/10.5194/amt-7-983-2014, 2014.

Murschell, T., Fulgham, S. R. and Farmer, D. K.: Gas-phase pesticide measurement using iodide ionization time-of-flight mass spectrometry, Atmos Meas Tech, 10(6), 2117-2127, https://doi.org/10.5194/amt-10-2117-2017, 2017. 
Nguyen, T. B., Bateman, A. P., Bones, D. L., Nizkorodov, S. A., Laskin, J. and Laskin, A.: High-resolution mass spectrometry analysis of secondary organic aerosol generated by ozonolysis of isoprene, Atmos. Environ., 44(8), 1032-1042, https://doi.org/10.1016/j.atmosenv.2009.12.019, 2010.

Ortega, J., Turnipseed, A., Guenther, A. B., Karl, T. G., Day, D. A., Gochis, D., Huffman, J. A., Prenni, A. J., Levin, E. J. T., Kreidenweis, S. M., DeMott, P. J., Tobo, Y., Patton, E. G., Hodzic, A., Cui, Y. Y., Harley, P. C., Hornbrook, R. S., Apel, E. C., Monson, R. K., Eller, A. S. D., Greenberg, J. P., Barth, M. C., Campuzano-Jost, P., Palm, B. B., Jimenez, J. L., Aiken, A. C., Dubey, M. K., Geron, C., Offenberg, J., Ryan, M. G., Fornwalt, P. J., Pryor, S. C., Keutsch, F. N., DiGangi, J. P., Chan, A. W. H., Goldstein, A. H., Wolfe, G. M., Kim, S., Kaser, L., Schnitzhofer, R., Hansel, A., Cantrell, C. A., Mauldin, R. L. and Smith, J. N.: Overview of the Manitou Experimental Forest Observatory: site description and selected science results from 2008 to 2013, Atmospheric Chem. Phys., 14(12), 6345-6367, https://doi.org/10.5194/acp-146345-2014, 2014.

Rivera-Rios, J. C., Nguyen, T. B., Crounse, J. D., Jud, W., St. Clair, J. M., Mikoviny, T., Gilman, J. B., Lerner, B. M., Kaiser, J. B., de Gouw, J., Wisthaler, A., Hansel, A., Wennberg, P. O., Seinfeld, J. H. and Keutsch, F. N.: Conversion of hydroperoxides to carbonyls in field and laboratory instrumentation: Observational bias in diagnosing pristine versus anthropogenically controlled atmospheric chemistry, Geophys. Res. Lett., 41(23), 2014GL061919, https://doi.org/10.1002/2014GL061919, 2014.

Stark, H., Yatavelli, R. L. N., Thompson, S. L., Kang, H., Krechmer, J. E., Kimmel, J. R., Palm, B. B., Hu, W., Hayes, P. L., Day, D. A., Campuzano-Jost, P., Canagaratna, M. R., Jayne, J. T., Worsnop, D. R. and Jimenez, J. L.: Impact of Thermal Decomposition on Thermal Desorption Instruments: Advantage of Thermogram Analysis for Quantifying Volatility Distributions of Organic Species, Environ. Sci. Technol., 51(15), 8491-8500, https://doi.org/10.1021/acs.est.7b00160, 2017.

Veres, P., Roberts, J. M., Warneke, C., Welsh-Bon, D., Zahniser, M., Herndon, S., Fall, R. and de Gouw, J.: Development of negative-ion proton-transfer chemical-ionization mass spectrometry (NI-PT-CIMS) for the measurement of gas-phase organic acids in the atmosphere, Int. J. Mass Spectrom., 274(1-3), 48-55, 2008.

Wang, X. K., Rossignol, S., Ma, Y., Yao, L., Wang, M. Y., Chen, J. M., George, C. and Wang, L.: Molecular characterization of atmospheric particulate organosulfates in three megacities at the middle and lower reaches of the Yangtze River, Atmospheric Chem. Phys., 16(4), 22852298, https://doi.org/10.5194/acp-16-2285-2016, 2016.

Wennberg, P. O., Bates, K. H., Crounse, J. D., Dodson, L. G., McVay, R. C., Mertens, L. A., Nguyen, T. B., Praske, E., Schwantes, R. H., Smarte, M. D., St Clair, J. M., Teng, A. P., Zhang, $\mathrm{X}$. and Seinfeld, J. H.: Gas-Phase Reactions of Isoprene and Its Major Oxidation Products, Chem. Rev., https://doi.org/10.1021/acs.chemrev.7b00439, 2018. 